(Catalysis Today)

\title{
Effects of Structure and Size of Ni Nanocatalysts on Hydrogen Selectivity via Water-Gas-Shift Reaction - A First-Principles-Based Kinetic Study
}

\author{
Mingxia Zhou ${ }^{1}$, Thong Nguyen-Minh Le ${ }^{2}$, Lam K. Huynh $^{3}$, and Bin Liu ${ }^{1} *$ \\ ${ }^{1}$ Department of Chemical Engineering, Kansas State University, 1005 Durland Hall, Manhattan, \\ Kansas 66506 \\ ${ }^{2}$ Molecular Science and Nano-Materials Laboratory, Institute for Computational Science and \\ Technology, Quang Trung Software Park, Dist. 12, Ho Chi Minh City, Vietnam \\ ${ }^{3}$ International University, Vietnam National University - Ho Chi Minh City, Vietnam
}

*Corresponding author: binliu@ksu.edu 


\begin{abstract}
The effects of structure and size of nickel nanocatalysts on hydrogen production via water-gas shift reaction (WGSR) were investigated using a first-principles-based kinetic model. Using periodic density functional theory and statistical calculations, thermochemistry and kinetics of the WGSR and competing methanation was calculated on $\mathrm{Ni}(111), \mathrm{Ni}(100)$, and $\mathrm{Ni}(211)$ facets. The kinetics of the elementary reactions involving $\mathrm{C}-\mathrm{H}, \mathrm{O}-\mathrm{H}$, and $\mathrm{C}-\mathrm{O}$ bond was found to fit to a general Brønsted-Evans-Polanyi (BEP) type linear relationship on all Ni facets considered. A mechanism describing the competition between the hydrogen and methane formation routes is constructed for further microkinetic modeling. The hydrogen production turnover frequency (TOF) via the WGSR route suggests the preference to the low-coordinated surface sites with the reaction activities following the order of $\mathrm{Ni}(211)>\mathrm{Ni}(100)>\mathrm{Ni}(111)$ using a simulated feed gas with a molar ratio of $\mathrm{CO}: \mathrm{H}_{2} \mathrm{O}=1: 2$. Due to the methanation, the TOF of methane production follows the same trend of hydrogen production. Consequently, the TOF of hydrogen production decreases with increasing particle diameters, due to the decreasing fractions of low-coordinated surface nickel atoms. It is also found that the presence of $\mathrm{H}_{2}$ in feed gas can largely enhance the methanation reaction.
\end{abstract}


Graphical Abstract

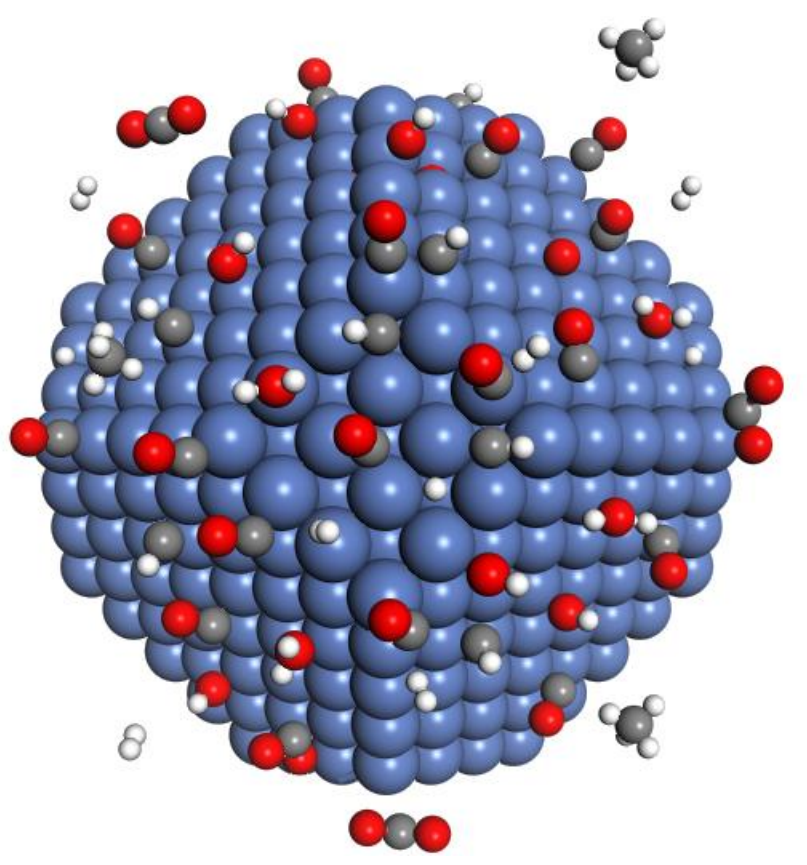




\author{
Abbreviations \\ WGSR - water-gas shift reaction; \\ DFT - density functional theory; \\ BEP - Brønsted-Evans-Polanyi; \\ $\mathrm{TOF}$ - turnover frequency; \\ VSAP - Vienna Ab initio Simulation Package; \\ GGA-PBE - generalized gradient approximation Perdew-Burke-Ernzerhof; \\ NEB - Nudged Elastic Band; \\ CatMAP - Catalysis Microkinetic Analysis Package; \\ $\mathrm{BE}$ - binding energies.
}

KEYWORDS: Density Functional Theory, microkinetic modeling, Ni nanocatalyst, selectivity, water-gas shift reaction 


\section{Introduction}

Hydrogen is an important clean fuel for efficient and clean power generation [1-3]. In addition, hydrogen is also widely used for fuel upgrading [4], ammonia synthesis [5], and fine chemicals production [6]. Steam reforming of hydrocarbons (e.g., $\mathrm{CH}_{4}$ as shown by Eqn. (1)) is a major industrial route to obtain hydrogen source in the form of syngas [7-9]. Alternative routes that utilize biomass-derived polyols (e.g., glycerol as shown in Eqn. (2)) have been successfully employed to demonstrate the feasibility of obtaining biorenewable hydrogen [10-12]. Water-gas shift reaction (WGSR) (Eqn. (3)) is ubiquitous in reforming reactions, and consumes CO to form $\mathrm{CO}_{2}$ and boost hydrogen production $[10,13]$. To a great extent, WGSR provides the benefits of boosting hydrogen productivity and mitigating catalyst poisoning effects by removing the strongbinding CO molecules from active sites [14-16].

$$
\begin{aligned}
& \mathrm{CH}_{4}(\mathrm{~g})+\mathrm{H}_{2} \mathrm{O}(\mathrm{g}) \rightleftharpoons \mathrm{CO}(\mathrm{g})+3 \mathrm{H}_{2}(\mathrm{~g}), \Delta \mathrm{H}^{\circ}{ }_{298 \mathrm{~K}}=206.2 \mathrm{~kJ} / \mathrm{mol} \\
& \mathrm{C}_{3} \mathrm{H}_{8} \mathrm{O}_{3}(\mathrm{l}) \rightleftharpoons 3 \mathrm{CO}(\mathrm{g})+4 \mathrm{H}_{2}(\mathrm{~g}), \Delta \mathrm{H}^{\circ}{ }_{298 \mathrm{~K}}=350 \mathrm{~kJ} / \mathrm{mol} \\
& \mathrm{H}_{2} \mathrm{O}(\mathrm{l})+\mathrm{CO}(\mathrm{g}) \rightleftharpoons \mathrm{CO}_{2}(\mathrm{~g})+\mathrm{H}_{2}(\mathrm{~g}), \Delta \mathrm{H}^{\circ}{ }_{298 \mathrm{~K}}=41.1 \mathrm{~kJ} / \mathrm{mol} \\
& \mathrm{CO}(\mathrm{g})+3 \mathrm{H}_{2}(\mathrm{~g}) \rightleftharpoons \mathrm{CH}_{4}(\mathrm{~g})+\mathrm{H}_{2} \mathrm{O}(\mathrm{l}), \Delta \mathrm{H}^{\circ}{ }_{298 \mathrm{~K}}=-206.2 \mathrm{~kJ} / \mathrm{mol}
\end{aligned}
$$

Like reforming, WGSR is also catalyzed on transition metals. Therefore, an important guiding principle in the search for optimal reforming catalysts is to enable effective $\mathrm{C}-\mathrm{H}, \mathrm{O}-\mathrm{H}$, and $\mathrm{C}-\mathrm{C}$ bond scissions [10]. Studies [17-20] performed on a number of monometallic catalysts suggest that $\mathrm{Ni}$ would exhibit promising reforming and WGSR activities, compared to $\mathrm{Co}, \mathrm{Cu}$, $\mathrm{Fe}, \mathrm{Ir}, \mathrm{Rh}, \mathrm{Ru}, \mathrm{Pt}$, and Pd. The natural abundance enables Ni-based catalysts to be an appealing material for practical, large-scale hydrogen production [21-23]. For $\mathrm{Ni}$, one of the challenges in heterogeneous catalysis is the tendency to cleave the $\mathrm{C}-\mathrm{O}$ bond via methanation (as in Eqn. (4)) [24, 25] or hydrogenolysis [20], adversely affecting hydrogen selectivity. The hydrogen production selectivity can be further manipulated by alloying [11] or chemical doping [26].

The WGSR pathways leading to hydrogen formation via different intermediates have been extensively elucidated using first-principles methods, as illustrated in Figure 1 [26-33]. Among different transition metals, the path via the carboxyl (i.e., $\mathrm{COOH}$, red path in Figure 1) intermediate is preferred on $\mathrm{Cu}(111)$ [27, 29], $\mathrm{Pt}(111)$ [28], and $\mathrm{Rh}(111)$ [30]. On $\mathrm{Ni}(111)$, both carboxyl and redox pathway are competitive [26, 33]. In comparison, the formate (HCOO) pathway is less competitive than the redox and carboxyl pathways [26-28, 31], and HCOO has 
been considered as a spectator species. Based on the analysis of such elementary mechanisms, the general kinetic trends of WGSR over various transition metal catalysts are understood [34, 35]. Particularly, microkinetic modelings based on the rate-determining steps (redox or carboxyl) has facilitated the assessment of the performance of monometallic WGSR catalysts.

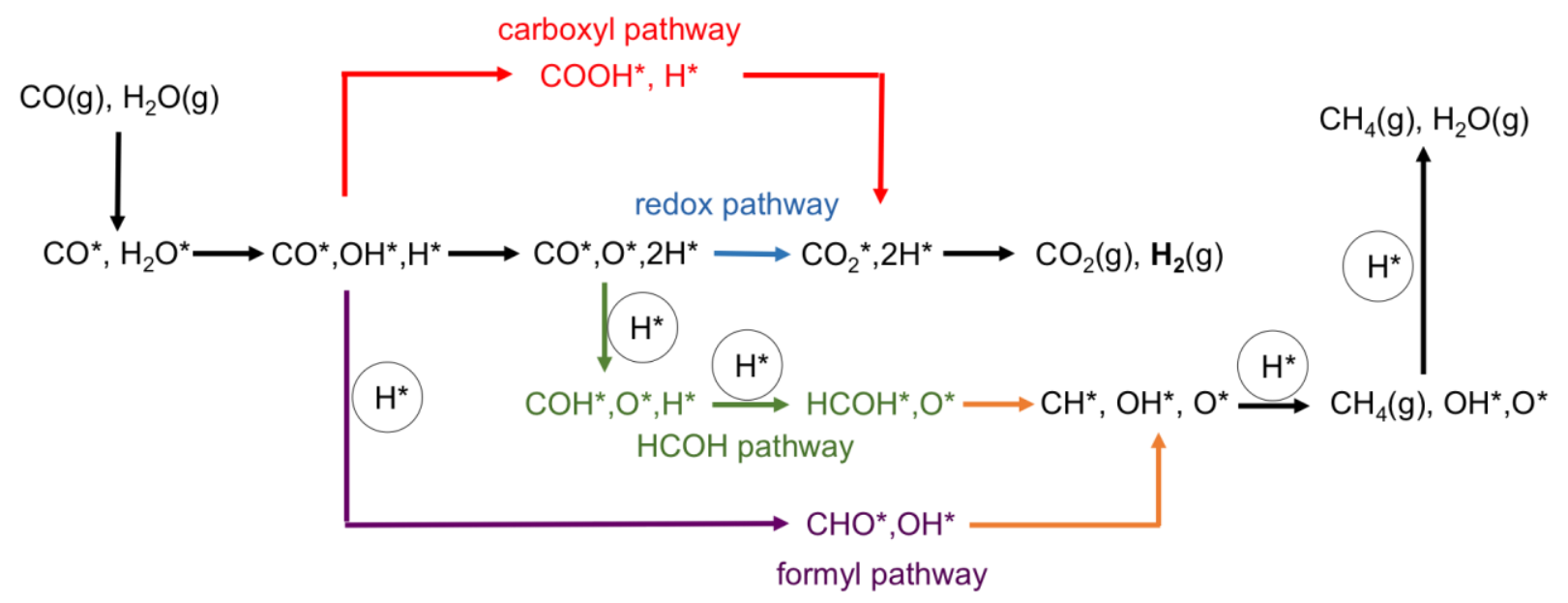

Figure 1. The reaction scheme illustrating the carboxyl (red) and redox (blue) pathways for hydrogen production; and the formyl (purple), and $\mathrm{HCOH}$ (green) pathways. The orange arrows represent $\mathrm{C}-\mathrm{O}$ bond scission steps. $\mathrm{H}^{*}$ in the circle represents hydrogen consumed due to methanation. The asterisks $(*)$ represent surface intermediates.

A systematic kinetic study on methanation via $\mathrm{CO}$ hydrogenation has been conducted by Vannice over group VIII metals [18], where $\mathrm{Ni}, \mathrm{Co}, \mathrm{Ru}$, and $\mathrm{Fe}$ are among the most active methanation catalysts. Methanation has also been extensively examined in the context of Fischer-Tropsch synthesis [36]. The detailed Fischer-Tropsch mechanism is still under debate, various reaction pathways have been investigated using density functional theory (DFT) calculations $[26,37,38]$ to reveal that the $\mathrm{C}-\mathrm{O}$ bond scission elementary steps are the ratedetermining step. Regarding $\mathrm{C}-\mathrm{O}$ bond scission, both direct and hydrogen-assisted methanation mechanisms have been proposed [26, 37, 39], where the energy barrier can be significantly reduced once $\mathrm{CO}$ is partially hydrogenated. The two main hydrogen-assisted $\mathrm{C}-\mathrm{O}$ bond scission pathways are illustrated in Figure 1, where the purple path involves the formation of a formyl group $(\mathrm{CHO})$ and the green path involves the formation of $\mathrm{COH}$. It has been shown that on $\mathrm{Ni}(111)$, the energy barriers can be significantly reduced [26]. 
This paper aims to elucidate the hydrogen selectivity on $\mathrm{Ni}$, where the adverse effect of methanation cannot be neglected. WGSR and methanation are both sensitive to catalyst surface structures [31, 37, 40]. Stamatakis et al. [40] performed kinetic Monte Carlo modeling of WGSR on $\operatorname{Pt}(111), \operatorname{Pt}(211)$, and $\operatorname{Pt}(322)$ at $180 \sim 345^{\circ} \mathrm{C}$ and 1 atm, and proposed that at low $\mathrm{CO}: \mathrm{H}_{2} \mathrm{O}$ ratios (e.g., $10^{-3}$ ), the step sites are much more active than the terraces sites; but at the $\mathrm{CO}: \mathrm{H}_{2} \mathrm{O}$ ratios of 0.5 , the coverages of $\mathrm{CO}$ and $\mathrm{H}$ and TOFs show less sensitivity to the surface structures. Catapan et al. [31] compared the WGSR and coke formation on $\mathrm{Ni}(111)$ and $\mathrm{Ni}(211)$ and concluded that the $\mathrm{Ni}(211)$ facet is more active for C-O bond scissions than Ni(111). Lowcoordination surface atoms, i.e., at the step sites, are able to enhance the binding of $\mathrm{H}_{2} \mathrm{O}$ [41] and $\mathrm{CO}$ and dissociate the adsorbates. The facilitated $\mathrm{H}_{2} \mathrm{O}$ dissociation is beneficial toward WGSR, however, the enhanced $\mathrm{C}-\mathrm{O}$ bond scission will also increase the selectivity to methanation. Therefore, a mechanistic understanding of the competition between WGSR and methanation and its structure-dependence will help address a fundamental heterogeneous catalysis issue.

Modern nanotechnologies have tremendously advanced the preparation of tailored nanocatalysts $[42,43]$. Control of nanoparticle shape and size will ultimately determine the dominant surface active terrace, edge, and corner sites. One prominent example of $\mathrm{CO}$ oxidation on gold demonstrated by Haruta et al. [44] suggests that catalytic activity and selectivity can be dramatically enhanced on highly dispersed nanoparticles $(<5 \mathrm{~nm})$. In WGSR, it has been found by Shekhar et al. that the low-coordinated corner Au sites can be seven times more active than the perimeter Au sites [45], both of which also depend on Au nanoparticle sizes. CO methanation is also found to be strongly dependent on the Ni nanoparticle sizes $(0.5 \sim 13 \mathrm{~nm})$ by van Meerten et al. [46]. A systematic investigation on the effect of Ni nanoparticle sizes (5 10, $10 \sim$ 20 , and $20 \sim 35 \mathrm{~nm}$ ) in $\mathrm{Ni} / \alpha-\mathrm{Al}_{2} \mathrm{O}_{3}$ on $\mathrm{CO}$ methanation by Gao et al. showed that nanoparticle size of $1 \sim 20 \mathrm{~nm}$ results in the highest $\mathrm{CO}$ turnover frequency (TOF) and $\mathrm{CH}_{4}$ yield [47].

In this work, using a uniform computational framework that consolidates periodic, spinpolarized DFT calculated thermochemistry and kinetics and the mean field kinetic modeling, we investigated the competition between WGSR and methanation to elucidate the key factors, i.e., temperature, surface coverage on hydrogen selectivity on nanoscale Ni catalysts. A mechanism consisting of only the dominant WGSR (i.e., redox and carboxyl pathways), and methanation pathways (i.e., $\mathrm{CHO}$ and $\mathrm{HCOH}$ pathways) was constructed [26]. The universal kinetic 
Brønsted-Evans-Polanyi (BEP) relationships describing elementary steps involving $\mathrm{C}-\mathrm{H}, \mathrm{O}-\mathrm{H}$, and $\mathrm{C}-\mathrm{O}$ bonds have also been established on $\mathrm{Ni}(111), \mathrm{Ni}(100)$, and $\mathrm{Ni}(211)$ facets.

\section{Computational methods}

\subsection{DFT calculations}

All DFT calculations were performed based on spin-polarized DFT calculations using Vienna ab initio simulation package (VASP) [48, 49]. The electron-ion interaction is described using the projector-augmented wave (PAW) method was used [50], with a plane wave energy cutoff of $385 \mathrm{eV}$. The generalized gradient approximation (GGA) PBE functional was used to calculate the electron exchange-correlation contributions [51]. The (111), (100), and (211) facets of single $\mathrm{Ni}$ crystal were used to represent the close-packed, open-packed, and step sites that are common in supported spherical or hemispherical face-centered cubic (FCC) transition metal nanoparticle surface [52]. Specifically, the Ni(111) surface is represented by a three-layer slab in a $3 \times 3$ hexagonal supercell; the $\mathrm{Ni}(100)$ surface represented by a three-layer $3 \times 3$ orthogonal supercell, and the $\mathrm{Ni}(211)$ surface represented by a three-layer $1 \times 3$ supercell, respectively. All supercells have a $20 \AA$ vacuum between any two neighboring successive slabs. The bottom two layers of each slab were fixed at the calculated bulk lattice value of $3.52 \AA$. The top layer of the slab and the adsorbed species were allowed to relax. The Brillouin-zone was sampled at with $4 \times$ $4 \times 1$ k-point mesh based on the Monkhorst-Pack scheme [53]. The electronic occupancy is determined by the Methfessel-Paxton scheme [54], with the width of smearing of $0.2 \mathrm{eV}$. The self-consistent iterations were converged to $1 \times 10^{-6} \mathrm{eV}$, and the geometry optimizations were stopped until the residual force is smaller than $0.02 \mathrm{eV} / \AA$.

Binding energies $(\mathrm{BE})$ were calculated using $\mathrm{BE}_{\mathrm{A}^{*}}=\mathrm{E}_{\mathrm{A}^{*}}-\mathrm{E}_{\mathrm{A}}-\mathrm{E}_{*}$, where $\mathrm{E}_{\mathrm{A}^{*}}$ is the total energy of the adsorbate $(A), E_{A}$ is the total energy of the adsorbate $(A)$ in gas phase calculated in a large box $(10 \AA \times 10 \AA \times 10.5 \AA)$, and $\mathrm{E}^{*}$ is the total energy of the clean surface. The energy barriers of elementary steps were calculated using a combined climbing image-Nudged Elastic Band (CI-NEB) [55] and dimer method [56], the latter of which was used to further refine the identified transition state structures. All calculated transition state structures were also confirmed using vibrational frequency analysis to show that there is only one imaginary frequency associated with each transition state. The energy barrier $\left(E_{a}\right)$ is calculated as $E_{a}=E_{T S}-E_{I S}$, where $\mathrm{E}_{\mathrm{TS}}$ is the total energy of the transition state and $\mathrm{E}_{\mathrm{IS}}$ is the total energy of the initial state, with 
reactant species treated at infinite separations. Vibrational frequency analysis was also performed on all reaction intermediates to approximate entropies and free energies.

The thermodynamic properties (e.g., entropy (S), enthalpy (H), and Gibbs free energy (G)) were calculated using the SurfKin package [57], where the translational, rotational, and vibrational entropies of gas phase and surface intermediates were calculated based on the standard statistical mechanical approach [58].

\subsection{Microkinetic modeling}

The descriptor-based Catalysis Microkinetic Analysis Package (CatMAP) [59], developed by Medford et al. for kinetic modelings of heterogeneous catalysis and electrocatalysis systems, was used to calculate the rates of WGSR and methanation and the surface coverages of reaction intermediates based on the mean field theory. The microkinetic model used in this study consists of 14 reaction steps, and 10 reaction intermediates. The flat $\mathrm{Ni}(111)$ and $\mathrm{Ni}(100)$ facets were modeled using two different surface sites: a "hydrogen reservoir" site [60], and site for all other intermediates. The stepped $\mathrm{Ni}(211)$ facet was modeled by considering three different sites: a "hydrogen reservoir" site, a "four-fold hollow" site and a site for all other intermediates. The detailed information are provided in the Supporting Information.

A temperature range of $423 \sim 723 \mathrm{~K}$, and a pressure of 1 bar were selected [35, 61, 62]. The formation energies of each reaction intermediate in the mechanism are calculated via explicit DFT calculations. $\mathrm{H}$ in gas phase $\mathrm{H}_{2}, \mathrm{O}$ in gas phase $\mathrm{H}_{2} \mathrm{O}$ and $\mathrm{C}$ in gas phase $\mathrm{CH}_{4}$ were used as the reference for $\mathrm{H}, \mathrm{O}$, and $\mathrm{C}$ species respectively. The energy barriers were taken from DFT calculations. The lateral interactions between adsorbates were not included in current modeling.

\subsection{Generation of Ni nanoparticles}

The $\mathrm{Ni}$ nanoparticle is assumed to have the shape of a truncated cuboctahedrons with predominant close-packed sites (i.e., (111)-like facet), open-packed sites (i.e., (100)-like facet), and step sites (i.e., (211)-like facet) [52]. To investigate the size-dependence, cuboctahedra consisting of various numbers of $\mathrm{Ni}$ atoms were generated, corresponding to diameters ranging from $1 \sim 8 \mathrm{~nm}$, measured as the distance between two opposite Ni(100) facets. The optimal (111), (100) and (211) fractions for each octahedron are determined according to the Wulff theorem so that the overall surface energies can be minimized [63]. 


\section{Results}

\subsection{Adsorptions of reaction intermediates}

Fourteen intermediate species were studied using periodic DFT calculations on the openpacked $\mathrm{Ni}(100)$ and stepped $\mathrm{Ni}(211)$ facets. The binding energies were then calculated based on their most stable configurations on respective surfaces. These binding energies and the preferred adsorption sites for all intermediates included in this study are listed in Table 1. The binding energies on close-packed $\mathrm{Ni}(111)$ have been reported in Ref. [26]. The adsorption structures on $\mathrm{Ni}(100)$ and $\mathrm{Ni}(211)$ are illustrated in Figure 2a and Figure 2b, respectively.

Table 1. Binding energies (BE), site preferences of reaction intermediates on $\mathrm{Ni}(111), \mathrm{Ni}(100)$, and $\mathrm{Ni}(211)$ surfaces.

\begin{tabular}{|l|l|l|l|l|l|l|l|}
\hline & \multicolumn{2}{|c|}{$\mathbf{N i}(\mathbf{1 1 1})^{\S}$} & \multicolumn{2}{c|}{$\mathbf{N i ( 1 0 0 )}$} & \multicolumn{2}{c|}{$\mathbf{N i ( 2 1 1 )}$} \\
\hline & & $\mathrm{BE}(\mathrm{eV})$ & site & $\mathrm{BE}(\mathrm{eV})$ & site & $\mathrm{BE}(\mathrm{eV})$ & site \\
\hline $\mathbf{1}$ & $\mathrm{H}_{2} \mathrm{O}$ & -0.27 & top & -0.36 & top & -0.55 & top \\
\hline $\mathbf{2}$ & $\mathrm{CO}$ & -1.93 & hcp & -1.88 & 4-fold hollow & -1.97 & hcp \\
\hline $\mathbf{3}$ & $\mathrm{CO}_{2}$ & -0.01 & top & -0.25 & 4-fold hollow & -0.38 & top-top \\
\hline $\mathbf{4}$ & $\mathrm{HCOH}$ & -3.88 & fcc & -4.19 & bridge & -4.53 & bridge \\
\hline $\mathbf{5}$ & $\mathrm{CH}_{2} \mathrm{OH}$ & -1.56 & fcc & -1.63 & bridge & -2.05 & bridge \\
\hline $\mathbf{6}$ & $\mathrm{H}$ & -2.80 & fcc & -2.73 & 4-fold hollow & -2.82 & hcp \\
\hline $\mathbf{7}$ & $\mathrm{OH}$ & -3.27 & fcc & -3.43 & 4-fold hollow & -3.78 & bridge \\
\hline $\mathbf{8}$ & $\mathrm{COOH}$ & -2.25 & bridge & -2.69 & 4-fold hollow & -2.18 & top-top \\
\hline $\mathbf{9}$ & $\mathrm{CHO}$ & -2.27 & fcc, hcp & -2.81 & bridge & -2.53 & bridge \\
\hline $\mathbf{1 0}$ & $\mathrm{CH}$ & -4.03 & fcc & -4.27 & 4-fold hollow & -4.11 & bridge \\
\hline $\mathbf{1 1}$ & $\mathrm{COH}$ & -4.39 & fcc, hcp & -4.67 & 4-fold hollow & -4.43 & hcp \\
\hline $\mathbf{1 2}$ & $\mathrm{O}$ & -5.39 & fcc & -5.61 & 4-fold hollow & -5.57 & hcp \\
\hline $\mathbf{1 3}$ & $\mathrm{CH}$ & -6.41 & fcc & -6.95 & 4-fold hollow & -6.67 & 4-fold hollow \\
\hline $\mathbf{1 4}$ & $\mathrm{C}$ & -6.89 & hcp & -8.22 & 4-fold hollow & -7.91 & 4-fold hollow \\
\hline
\end{tabular}

${ }^{\S}$ Data taken from Ref. [26].

A brief overview of the binding energies and their preferred binding sites of the studied intermediates will help explain the thermodynamics and surface coverages in subsequent modelings. On $\mathrm{Ni}(100)$ and $\mathrm{Ni}(211), \mathrm{H}_{2} \mathrm{O}$ adsorbs on the top site, and the respective binding energies are $-0.55 \mathrm{eV}$ and $-0.36 \mathrm{eV}$, versus $-0.27 \mathrm{eV}$ on $\mathrm{Ni}(111)$. $\mathrm{CO}$ binds on the 4-fold hollow site and the hcp site of the respective $\mathrm{Ni}(100)$ and $\mathrm{Ni}(211)$ facets. The $\mathrm{CO}$ binding energies are $1.88 \mathrm{eV}$ and $-1.97 \mathrm{eV}$, which are comparable to that on the $\mathrm{Ni}(111) . \mathrm{CO}_{2}$ binds much stronger on the 4-fold hollow site and the top-top site of $\mathrm{Ni}(100)$ and $\mathrm{Ni}(111)$ facets, at $-0.25 \mathrm{eV}$ and -0.38 
$\mathrm{eV}$, respectively, versus that of $-0.01 \mathrm{eV}$ on $\mathrm{Ni}(111)$. $\mathrm{HCOH}$ also binds stronger, at respective $4.19 \mathrm{eV}$ and $-4.53 \mathrm{eV}$, at the bridge sites of respective $\mathrm{Ni}(100)$ and $\mathrm{Ni}(211)$ facets than on $\mathrm{Ni}(111)$. $\mathrm{CH}_{2} \mathrm{OH}$ binds stronger on $\mathrm{Ni}(100)$ and $\mathrm{Ni}(211)$ at the bridge sites, with binding energies of $-1.63 \mathrm{eV}$ and $-2.05 \mathrm{eV}$, respectively, as well. $\mathrm{H}$ binds at the 4-fold hollow site and the hop site on $\mathrm{Ni}(100)$ and $\mathrm{Ni}(211)$. The binding energy of $\mathrm{H}$ on $\mathrm{Ni}(100)$ is $-2.73 \mathrm{eV}$, slightly weaker than that on the $\mathrm{Ni}(111)$, while $\mathrm{H}$ binds slightly stronger at $-2.82 \mathrm{eV}$ than that on the $\mathrm{Ni}(111) . \mathrm{OH}$ binds stronger than that on $\mathrm{Ni}(111)$ at the 4-fold hollow site and the bridge site of $\mathrm{Ni}(100)$ and $\mathrm{Ni}(211)$ at $-3.43 \mathrm{eV}$ and $-3.78 \mathrm{eV}$, respectively. $\mathrm{COOH}$ binds much stronger at the 4-fold hollow at $-2.69 \mathrm{eV}$ (versus $-2.25 \mathrm{eV}$ on $\mathrm{Ni}(111)$ ), however, the binding is weaker on $\mathrm{Ni}(211)$ at $-2.18 \mathrm{eV}$ at the top-top site. $\mathrm{CHO}$ also binds much stronger on the bridge site of $\mathrm{Ni}(100)$ at $-2.81 \mathrm{eV}$ (versus $-2.27 \mathrm{eV}$ on $\mathrm{Ni}(111)$ ). $\mathrm{CHO}$ also prefers to bind at the bridge site of $\mathrm{Ni}(211)$ at $-2.53 \mathrm{eV}$, again stronger than on $\mathrm{Ni}(111) . \mathrm{CH}_{2}$ binds at the 4-fold hollow site and bridge site of respective $\mathrm{Ni}(100)$ and $\mathrm{Ni}(211)$ at $-4.27 \mathrm{eV}$ and $-4.11 \mathrm{eV}$ compared to $-4.08 \mathrm{eV}$ on $\mathrm{Ni}(111)$. $\mathrm{COH}$ binds at the 4-fold hollow site of $\mathrm{Ni}(100)$ and the hcp site of $\mathrm{Ni}(211)$, at $-4.67 \mathrm{eV}$ and $-4.43 \mathrm{eV}$ respectively compared to $-4.39 \mathrm{eV}$ on $\mathrm{Ni}(111)$. $\mathrm{O}$ binds at the 4 -fold hollow site of $\mathrm{Ni}(100)$ and the hcp site of $\mathrm{Ni}(211)$ surface with respective binding energies of $-5.61 \mathrm{eV}$ and $-5.57 \mathrm{eV}$, both of which are stronger than on the $\mathrm{Ni}(111)$ surface. $\mathrm{CH}$ binds at the 4-fold hollow of $\mathrm{Ni}(100)$ and the 4-fold hollow of the step on $\mathrm{Ni}(211)$ with binding energies of $-6.95 \mathrm{eV}$ and $-6.67 \mathrm{eV}$, respectively. Similar to $\mathrm{CH}, \mathrm{C}$ also binds on the 4 -fold hollow sites of $\mathrm{Ni}(100)$ and $\mathrm{Ni}(211)$ with much stronger $(>1.0 \mathrm{eV}$ ) bind energies at $-8.22 \mathrm{eV}$ and $-7.91 \mathrm{eV}$ in comparison to $-6.89 \mathrm{eV}$ on $\mathrm{Ni}(111)$.

All intermediates bind stronger on $\mathrm{Ni}(100)$ and $\mathrm{Ni}(211)$ facets in general, except for $\mathrm{CO}$ and $\mathrm{H}$ on the (100) facet, and $\mathrm{COOH}$ on $\mathrm{Ni}(211)$. $\mathrm{CO}$ and $\mathrm{H}$ still prefer the hcp 3-fold sites on $\mathrm{Ni}(211)$, where the low-coordination edge $\mathrm{Ni}$ atoms play negligible role in enhancing the binding of $\mathrm{CO}$ and $\mathrm{H}$. However, the intermediates participating in $\mathrm{CO}$ methanation - e.g., $\mathrm{CHO}, \mathrm{CH}, \mathrm{O}-$ bind much stronger on $\mathrm{Ni}(211)$ and $\mathrm{Ni}(100)$. 
(a)
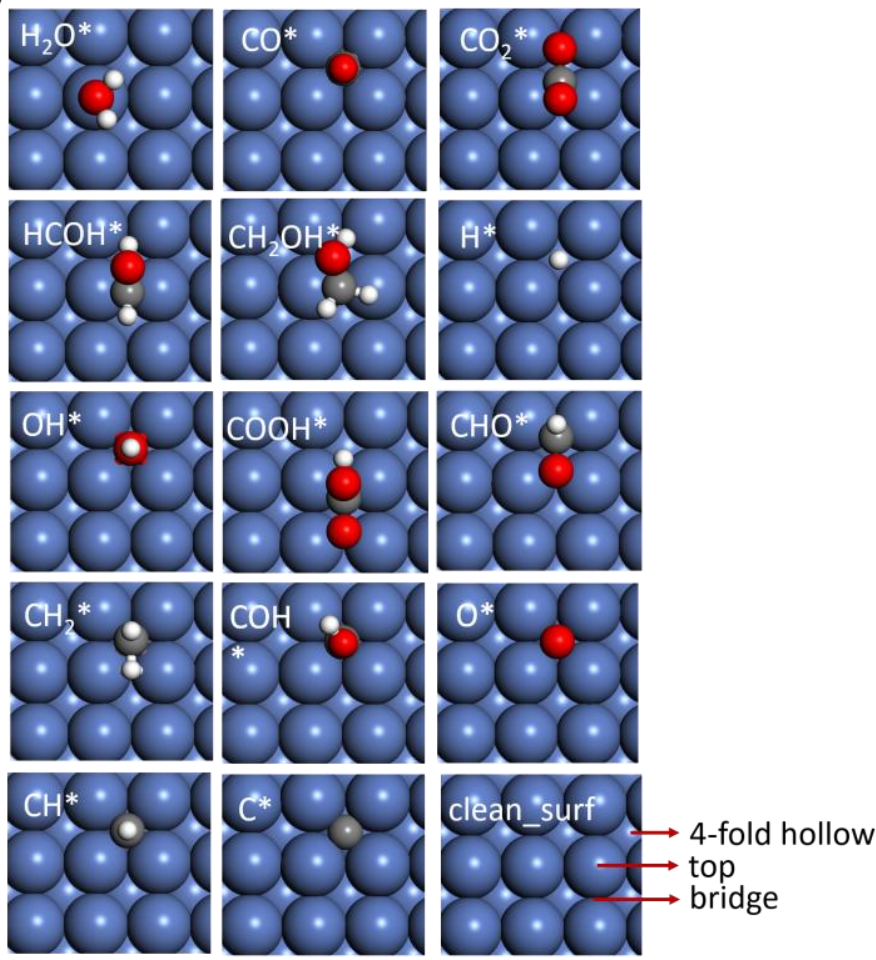

(b)
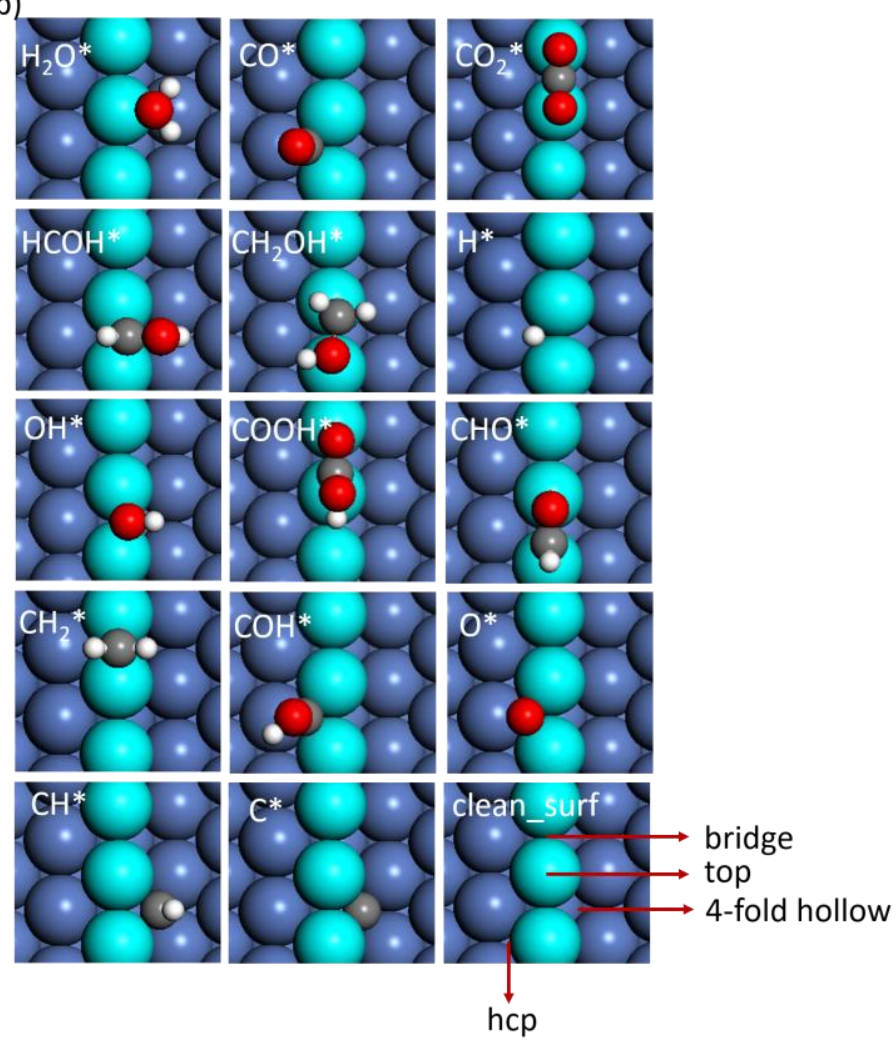

Figure 2. Optimized structures of the clean surface and the 14 intermediates in Table 1 on (a) $\mathrm{Ni}(100)$, and (b) $\mathrm{Ni}(211)$. The grey, red, white, and blue spheres represent $\mathrm{C}, \mathrm{O}, \mathrm{H}$, and 
$\mathrm{Ni}$, respectively. The edge $\mathrm{Ni}$ atoms in $\mathrm{Ni}(211)$ are highlighted in turquoise. The adsorption sites on $\mathrm{Ni}(100)$ and $\mathrm{Ni}(211)$ are marked on the clean surface.

\subsection{BEP relationship}

A BEP relationship can reveal a linear correlation between the transition state energy and the corresponding reaction energy of an elementary step [64, 65]. Consequently, BEP relationships provide a means for fast estimation of reaction kinetics $[13,66,67]$. In this study, the elementary steps involving $\mathrm{C}-\mathrm{H}, \mathrm{O}-\mathrm{H}$ bonds and $\mathrm{C}-\mathrm{O}$ bonds on the (111), (100), and (211) facets were investigated. The transition state energies $\left(\mathrm{E}_{\mathrm{TS}}\right)$ and final state energies $\left(\mathrm{E}_{\mathrm{FS}}\right)$ relative to gas phase initial state energies were used to obtain the BEP relationship (Figure 3 (a) and (b)). The transition state structures are shown in Supporting Information (Figure S1).

Using the results obtained from DFT calculations on the (111) facet (blue dots), a linear relationship for both $\mathrm{C}-\mathrm{O}$ bond forming/scission or C-H/O-H bond forming/scission clearly exist as described by Figure 3(a) and 3(b), with the mean absolute error (MAE) of $0.24 \mathrm{eV}$ and 0.25 $\mathrm{eV}$ for $\mathrm{C}-\mathrm{O}$ bond scission and $\mathrm{C}-\mathrm{H} / \mathrm{O}-\mathrm{H}$ bond scission reactions, respectively. The slope and intercept for $\mathrm{C}-\mathrm{O}$ bond cleavage/forming reaction are 0.91 and $1.16 \mathrm{eV}$ while the corresponding values for $\mathrm{C}-\mathrm{H} / \mathrm{O}-\mathrm{H}$ bond cleavage/forming reaction are 0.92 and $0.93 \mathrm{eV}$ on $\mathrm{Ni}(111)$. The slope of $\mathrm{C}-\mathrm{H} / \mathrm{O}-\mathrm{H}$ bond relationship (0.92) is in good agreement with that (0.96) developed by Mohsenzadeh et al.[33] using a dataset that combines $\mathrm{Ni}(111), \mathrm{Ni}(100)$ and $\mathrm{Ni}(110)$ facets; and 0.86 obtained by Catapan et al. for just $\mathrm{Ni}(111)$ [31]. The $\mathrm{C}-\mathrm{O}$ bond BEP relationship is in good agreement with that developed by Catapan as well [31].

It should be noted that, unlike the BEP developed in other literature, this work intends to test the generality of the BEP relationship using only a subset of kinetic data, i.e., $\mathrm{Ni}(111)$. We believe that the BEP relationship developed on $\mathrm{Ni}(111)$ has the predictive power for $\mathrm{Ni}(211)$ and $\mathrm{Ni}(100)$. In order to further demonstrate the applicability of such linear relationships on $\mathrm{Ni}(100)$ and $\mathrm{Ni}(211)$, additional DFT calculations on a subset of the elementary steps on $\mathrm{Ni}(100)$ (green dots) and $\mathrm{Ni}(211)$ (red dots) were included in Figure 3. Seven elementary steps are calculated for testing C-O bond cleavage/forming reaction, including: $\mathrm{CO}^{*}+\mathrm{O}^{*} \leftrightarrow \mathrm{CO}_{2}^{*}+*, \mathrm{CO}^{*}+\mathrm{OH}^{*} \leftrightarrow$ $\mathrm{COOH}^{*}+*, \mathrm{CO}^{*}+* \leftrightarrow \mathrm{C}^{*}+\mathrm{O}^{*}, \mathrm{CHO}^{*}+* \leftrightarrow \mathrm{CH}^{*}+\mathrm{O}^{*}, \mathrm{COH}^{*}+* \leftrightarrow \mathrm{C}^{*}+\mathrm{OH}^{*}, \mathrm{HCOH}^{*}+$ $* \leftrightarrow \mathrm{CH}^{*}+\mathrm{OH}^{*}$, and $\mathrm{CH}_{2} \mathrm{OH}^{*}+* \leftrightarrow \mathrm{CH}_{2}^{*}+\mathrm{OH}^{*}$. In the meantime, five elementary steps are 
calculated for testing $\mathrm{C}-\mathrm{H} / \mathrm{O}-\mathrm{H}$ bond cleavage/forming, including $\mathrm{H}_{2} \mathrm{O}^{*}+* \leftrightarrow \mathrm{H}^{*}+\mathrm{OH}^{*}, \mathrm{OH}^{*}$ $+^{*} \leftrightarrow \mathrm{O}^{*}+\mathrm{H}^{*}, \mathrm{COOH}^{*}+* \leftrightarrow \mathrm{CO}_{2}^{*}+\mathrm{H}^{*}, \mathrm{CO}^{*}+\mathrm{H}^{*} \leftrightarrow \mathrm{CHO}^{*}+*, \mathrm{CO}^{*}+\mathrm{H}^{*} \leftrightarrow \mathrm{COH}^{*}+*$. It can be seen that the same steps on the less-packed terrace sites and steps sites indeed follow the same linear relationships reasonably well. The energy barriers of the elementary steps are listed in Table S1.

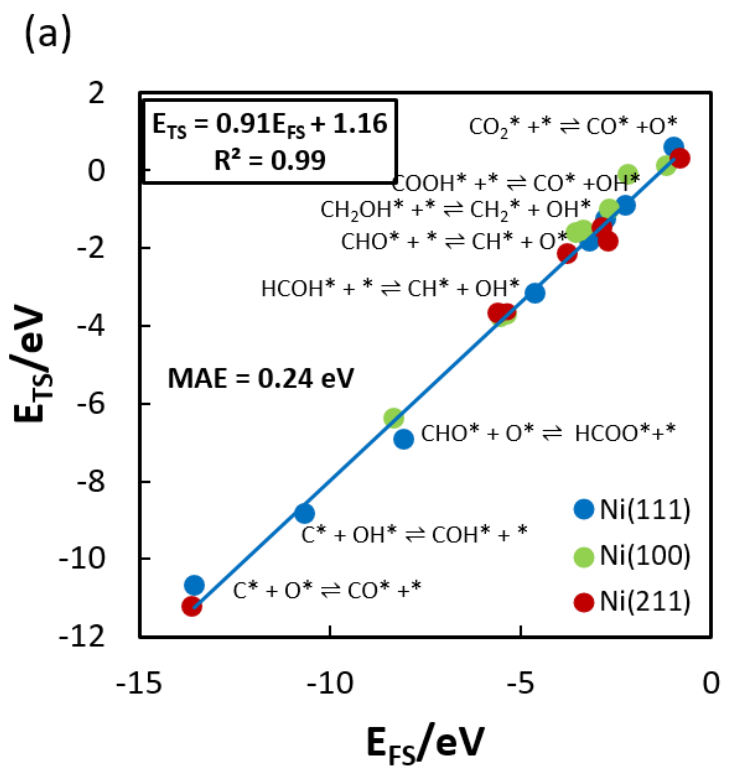

(b)

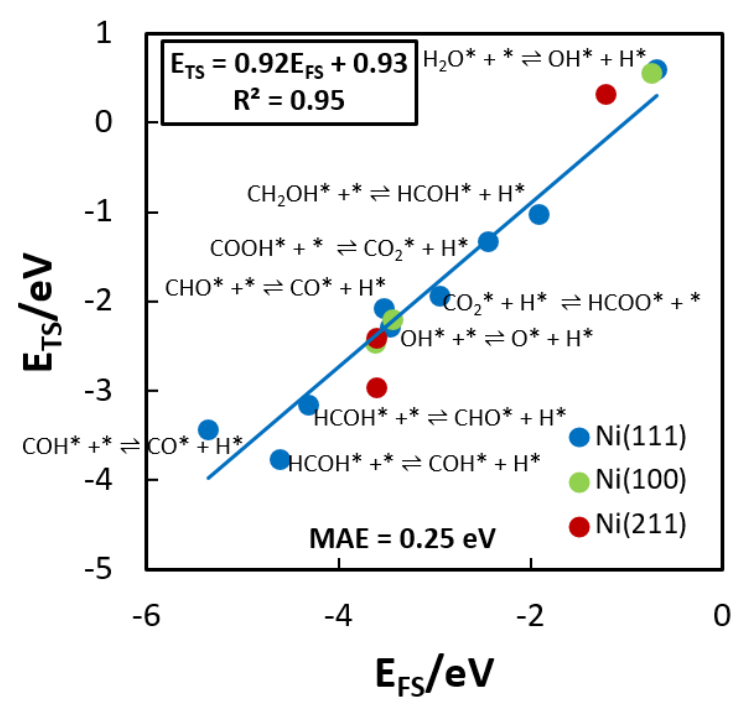

Figure 3. (a) BEP relationship for $\mathrm{C}-\mathrm{O}$ bond forming/scission; (b) BEP relationship for $\mathrm{C}-\mathrm{H} / \mathrm{O}-$ $\mathrm{H}$ bond forming/scission. The elementary steps are expressed in the exothermic direction. $\mathrm{E}_{\mathrm{FS}}$ and $\mathrm{E}_{\mathrm{TS}}$ are relative energies to gas phase initial state energies. 


\subsection{Free energy diagrams of WGSR and methanation on $\mathrm{Ni}(111)$, Ni(100), and Ni(211)}

WGSR is a moderately exothermic reaction (as shown in Eqn. (1)), and the thermochemistry favors $\mathrm{CO}$ conversion at low temperatures (in the range of 423K $~ 513 \mathrm{~K}$ ). Nevertheless, WGSR at intermediate and high temperatures (up to $1000 \mathrm{~K}$ under steam reforming conditions) are still relevant in many applications [68, 69]. Figure 4 presents the DFT-based free energies of WGSR redox and carboxyl pathways on the (111), (100), and (211) facets. The free energies were estimated at $600 \mathrm{~K}$ and $1 \mathrm{bar}$, using gas phase $\mathrm{CO}, \mathrm{H}_{2} \mathrm{O}$ and clean surface as the energy reference. Free energies estimated for both WGSR and CO methanation at other temperatures are reported in Table S2 4 in the Supporting Information.

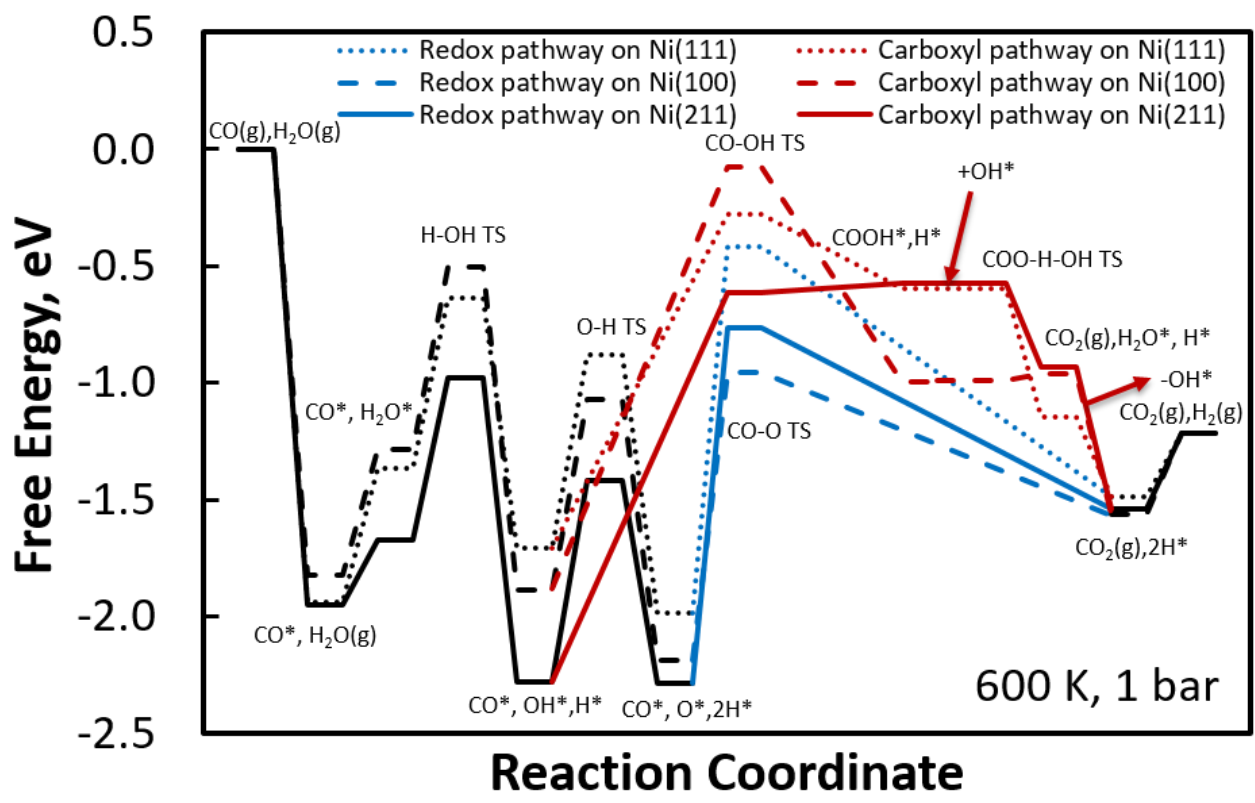

Figure 4. Free energy diagrams representing the redox and carboxyl pathways on Ni(111), $\mathrm{Ni}(100)$, and $\mathrm{Ni}(211)$ surface at $600 \mathrm{~K}$ and 1 bar. The black path represents $\mathrm{CO}$ adsorption, $\mathrm{H}_{2} \mathrm{O}$ adsorption, dissociation, and $\mathrm{H}_{2}$ formation.

Water dissociation is enhanced on $\mathrm{Ni}(211)$ (black solid paths in Figure 4) [70]. On Ni(100), the $\mathrm{OH}$ dissociation step forming $\mathrm{O}$ becomes even more exothermic (black dashed path), which is consistent with the findings by Mohsenzadeh et al. [33]. The enhanced water dissociation is expected to boost WGSR and hydrogen production by supplying the essential $\mathrm{H}, \mathrm{O}$, and $\mathrm{OH}$ species. 
Direct $\mathrm{CO}$ oxidation by $\mathrm{O}$ from water dissociation occurs in the redox pathways forming $\mathrm{CO}_{2}$, represented by the solid, dashed, and dotted paths for (211), (100), and (111) in Figure 4, respectively. It can be seen in Figure 4 that the $\mathrm{CO}$ oxidation step remains the rate-limiting step on all three facets studied. The redox pathways corresponding to the $\mathrm{Ni}(100)$ and $\mathrm{Ni}(211)$ facets shift downward in the free energy diagram compared to the closed-packed $\mathrm{Ni}(111)$, due to the enhanced water dissociation and $\mathrm{CO}$ oxidation thermochemistry.

The carboxyl pathway is another competitive WGSR route, with $\mathrm{CO}$ reacts with $\mathrm{OH}$ forming $\mathrm{COOH}$ being the rate-limiting step. On $\mathrm{Ni}(100)$ and $\mathrm{Ni}(211)$, the carboxyl pathway remains competitive, with $\mathrm{COOH}$ formation step being rate-limiting. The free energies of the carboxyl pathway on $\mathrm{Ni}(211)$ shift downward when compared to the $\mathrm{Ni}(111)$ facet, due to the enhanced water dissociation that produces the $\mathrm{OH}$ species. It is also intriguing to note that the rate-limiting step on $\mathrm{Ni}(100)$ shifts upward, due to the increased energy barrier of $\mathrm{COOH}$ formation, making the carboxyl pathway the least kinetically favorable.

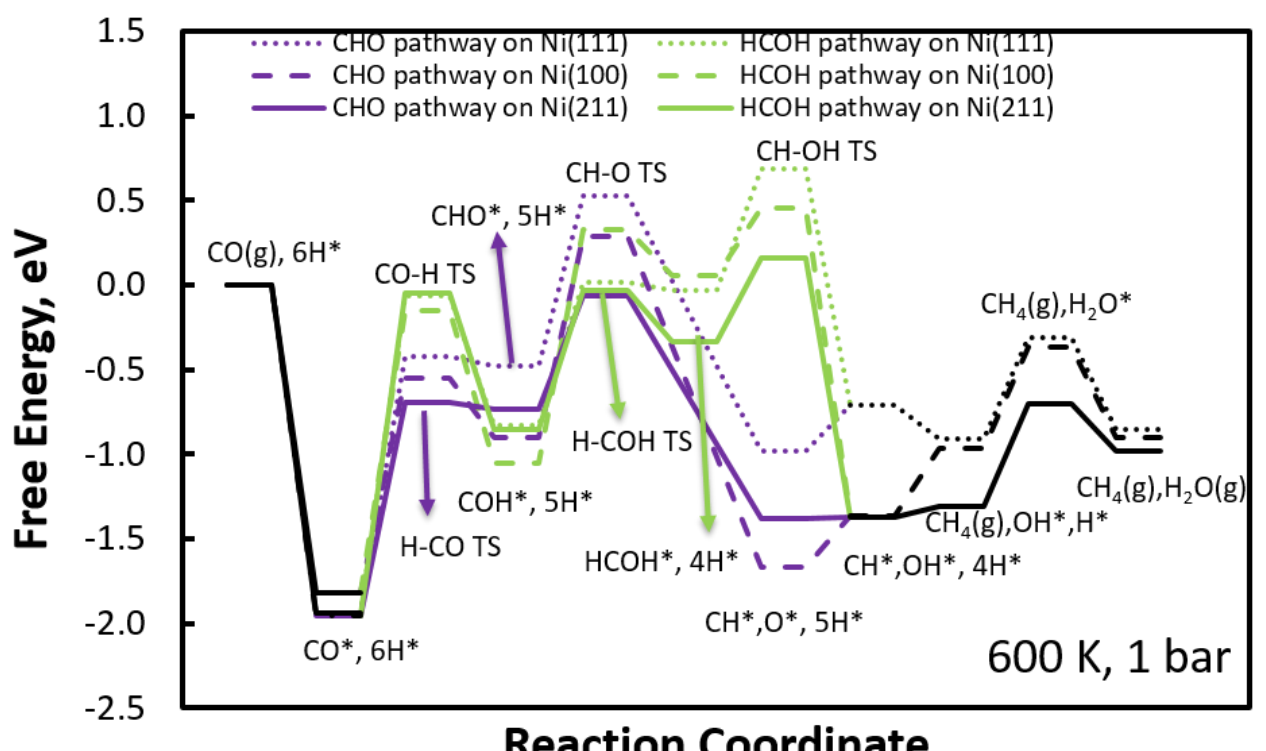

Figure 5. Free energy diagrams of the formyl (purple) and $\mathrm{HCOH}$ (green) pathway on $\mathrm{Ni}(111)$, $\mathrm{Ni}(100)$, and $\mathrm{Ni}(211)$ facets at $600 \mathrm{~K}$ and 1 bar. The black path represents $\mathrm{CO}$ adsorption, $\mathrm{H}_{2} \mathrm{O}$ adsorption, dissociation, and $\mathrm{CH}_{4}$ formation steps. 
The free energy diagrams depicting $\mathrm{CO}$ methanation via the formyl and $\mathrm{HCOH}$ pathways on $\mathrm{Ni}(111), \mathrm{Ni}(100)$, and $\mathrm{Ni}(211)$ at $600 \mathrm{~K}$ and 1 bar are shown in Figure 5. Gas phase $\mathrm{CO}$, and adsorbed $\mathrm{H}$ are chosen as the zero energy reference. The $\mathrm{C}-\mathrm{O}$ bond scissions of the $\mathrm{CHO}$ and $\mathrm{HCOH}$ intermediates are the rate-limiting steps of respective pathways. The formation of $\mathrm{CHO}^{*}$ are exothermic on all facets, and $\mathrm{Ni}(211)$ enables the lowest energy barrier for $\mathrm{CO}$ hydrogenation. The energy barriers of the $\mathrm{C}-\mathrm{O}$ bond scission in $\mathrm{CHO}$ are lower on $\mathrm{Ni}(211)$ and $\mathrm{Ni}(100)$ facets. The formyl pathway on $\mathrm{Ni}(211)$ has the lowest overall free energies, mainly due to the much lower energy barrier for $\mathrm{C}-\mathrm{O}$ bond scission in $\mathrm{CHO}$.

$\mathrm{HCOH}$ pathway involves $\mathrm{COH}$ as an intermediate species. $\mathrm{CO}$ hydrogenation, forming $\mathrm{COH}^{*}$ are endothermic on all facets and $\mathrm{Ni}(100)$ has lowest energy barrier. The formation of $\mathrm{HCOH}^{*}$ are still endothermic and $\mathrm{Ni}(211)$ has lowest energy barrier. The $\mathrm{C}-\mathrm{O}$ bond scission from $\mathrm{HCOH}^{*}$ is exothermic on all facets and the energy barrier decrease in order of $\mathrm{Ni}(111)>$ $\mathrm{Ni}(100)>\mathrm{Ni}(211)$. Overall, the formyl pathway and the $\mathrm{HCOH}$ pathway are both competitive pathways on $\mathrm{Ni}(211)$.

\section{Kinetic modeling and discussion}

\subsection{First-principles-based mechanism for microkinetic modeling}

The influence of CO methanation on hydrogen selectivity and the structure and size-dependence on Ni nanocatalysts have been investigated by carrying out mean-field theory-based microkinetic modelings. A mechanism consisting of 14 reaction steps, including the redox and carboxyl pathways (R4 R7, for WGSR), the formyl and $\mathrm{HCOH}$ pathways (R9 $\sim \mathrm{R} 13$, for methanation), $\mathrm{CO}$ adsorption (R1), $\mathrm{H}_{2} \mathrm{O}$ dissociation (R2, R3), and $\mathrm{H}_{2}$, and $\mathrm{CH}_{4}$ formation steps (R8, R14) for microkinetic modeling are constructed: 


$\begin{array}{ll}\mathrm{CO}(\mathrm{g})+* \leftrightarrow \mathrm{CO}^{*} & \mathrm{R} 1 \\ \mathrm{H}_{2} \mathrm{O}(\mathrm{g})+2^{*} \leftrightarrow \mathrm{OH}^{*}+\mathrm{H}^{*} & \mathrm{R} 2 \\ \mathrm{OH}^{*}+* \leftrightarrow \mathrm{O}^{*}+\mathrm{H}^{*} & \mathrm{R} 3 \\ \mathrm{CO}^{*}+\mathrm{O}^{*} \leftrightarrow \mathrm{CO}_{2}(\mathrm{~g})+2^{*} & \mathrm{R} 4 \\ \mathrm{CO}^{*}+\mathrm{OH}^{*} \leftrightarrow \mathrm{COOH}^{*}+* & \mathrm{R} 5 \\ \mathrm{COOH}^{*} \leftrightarrow \mathrm{CO}_{2}(\mathrm{~g})+\mathrm{H}^{*} & \mathrm{R} 6 \\ \mathrm{COOH}^{*}+\mathrm{OH}^{*} \leftrightarrow \mathrm{CO}_{2}(\mathrm{~g})+\mathrm{H}_{2} \mathrm{O}(\mathrm{g})+2^{*} & \mathrm{R} 7 \\ 2 \mathrm{H}^{*} \leftrightarrow \mathrm{H}_{2}(\mathrm{~g})+2 * & \mathrm{R} 8 \\ \mathrm{CO}^{*}+\mathrm{H}^{*} \leftrightarrow \mathrm{CHO}^{*}+* & \mathrm{R} 9 \\ \mathrm{CHO}^{*}+{ }^{*} \leftrightarrow \mathrm{CH}^{*}+\mathrm{O}^{*} & \mathrm{R} 10 \\ \mathrm{CO}^{*}+\mathrm{H}^{*} \leftrightarrow \mathrm{COH}^{*}+* & \mathrm{R} 11 \\ \mathrm{COH}^{*}+\mathrm{H}^{*} \leftrightarrow \mathrm{HCOH}^{*}+* & \mathrm{R} 12 \\ \mathrm{HCOH}^{*}+{ }^{*} \leftrightarrow \mathrm{CH}^{*}+\mathrm{OH}^{*} & \mathrm{R} 13 \\ \mathrm{CH}^{*}+3 \mathrm{H}^{*} \leftrightarrow \mathrm{CH}_{4}(\mathrm{~g})+4^{*} & \mathrm{R} 14\end{array}$

The asterisk (*) represents the open site on $\mathrm{Ni}(111), \mathrm{Ni}(100)$, or $\mathrm{Ni}(211)$, and will be differentiated in the kinetic modeling. Particularly, ' $\mathrm{H}$ reservoir' sites were created, as implemented by Medford et al. [60]. The detailed mechanisms for respective Ni(111), Ni(100), and $\mathrm{Ni}(211)$ facets and $\mathrm{Ni}$ nanocatalysts are shown in Supporting Information. Reactions R4 and R5 are identified as the rate-determining steps for WGSR as discussed in Section 3.3.

There are still debates regarding the actual rate-limiting steps for microkinetic modeling of $\mathrm{CO}$ methanation [71]. In this paper, $\mathrm{C}-\mathrm{O}$ bond dissociation (R10 and R13) are both treated as the rate-limiting steps based on the first-principles calculations. The energy barriers for water dissociation, i.e., R2 and R3, are also explicitly included due to its sensitivity of these steps to surface structures (as shown in Figure 4). In addition, the energy barriers of CO hydrogenation steps were also included.

Gas phase $\mathrm{H}_{2}$ and adsorbed $\mathrm{H}^{*}$ are in thermodynamic equilibrium, which is an assumption adopted by Sehested et al. [71]. The $\mathrm{CH}^{*}$, which is a major intermediates from $\mathrm{C}-\mathrm{O}$ bond 
scission, is also considered to react quickly forming $\mathrm{CH}_{4}$ under the simulated conditions. Again, such approximation has been proposed and used by Vannice, who assumes that $\mathrm{CH}_{\mathrm{y}}$ hydrogenation steps will not influence the kinetics of the overall methanation [72]. In our kinetic modeling, the energy barriers for both $\mathrm{H}_{2}$ and $\mathrm{CH}_{4}$ formations have been neglected.

\subsection{Ni nanocatalyst facets and size effects on reactivity and selectivity dependence}

Figure 6 shows the $\mathrm{H}_{2}$ and $\mathrm{CH}_{4}$ production rates based on the microkinetic modeling conducted at a temperature range of $423 \sim 723 \mathrm{~K}$ and the pressure of 1 bar on $\mathrm{Ni}(111), \mathrm{Ni}(100)$, and $\mathrm{Ni}(211)$ facets. The simulated feed composition, with a representative molar ratio of $\mathrm{CO}: \mathrm{H}_{2} \mathrm{O}=1: 2$ [73], was used. The production rates on different single Ni crystal facets are represented in terms of the turnover frequency (TOF in $\mathrm{s}^{-1}$ ). The TOF order for both $\mathrm{H}_{2}$ and $\mathrm{CH}_{4}$, corresponding to the rates of WGSR and methanation, are in good agreement with the free energy diagram (Figures 4 and 5). The vertical dashed line indicates the TOF for the temperature of $600 \mathrm{~K}$.

In Figure 6, both the $\mathrm{H}_{2}$ and $\mathrm{CH}_{4}$ production rate increase with the temperature, which suggest that the reaction system is still kinetically controlled. In principle, this could be due to the lack of explicit consideration of the adsorbate-adsorbate interactions in our microkinetic models. In fact, the CO surface coverage has been found to be over-estimated and would be likely to hinder the surface to reach thermodynamic equilibrium. Nevertheless, we believe that the analysis will not be affected by this limitation in the current model.

Figure 6 shows that the $\mathrm{H}_{2}$ production rate decreases in the order of $\mathrm{Ni}(211)>\mathrm{Ni}(100)>$ $\mathrm{Ni}(111)$, and the same trend has been observed for $\mathrm{CH}_{4}$ production rate. At feed composition of $\mathrm{CO}: \mathrm{H}_{2} \mathrm{O}=1: 2$, the $\mathrm{H}_{2}$ production rate is much higher on all $\mathrm{Ni}$ facets than the $\mathrm{CH}_{4}$ production rate. Among the $\mathrm{Ni}(111), \mathrm{Ni}(100)$, and $\mathrm{Ni}(211)$ facets, the difference in TOFs for $\mathrm{H}_{2}$ productions (solid lines) is much smaller than that for $\mathrm{CH}_{4}$ productions (dashed lines). Qualitatively, the modeling suggests that although reaction rates are higher on the $\mathrm{Ni}(211)$ step edge sites, methanation is much more sensitive to these low-coordination $\mathrm{Ni}$ atoms that facilitates the $\mathrm{C}-\mathrm{O}$ bond scission rate-limiting steps. 


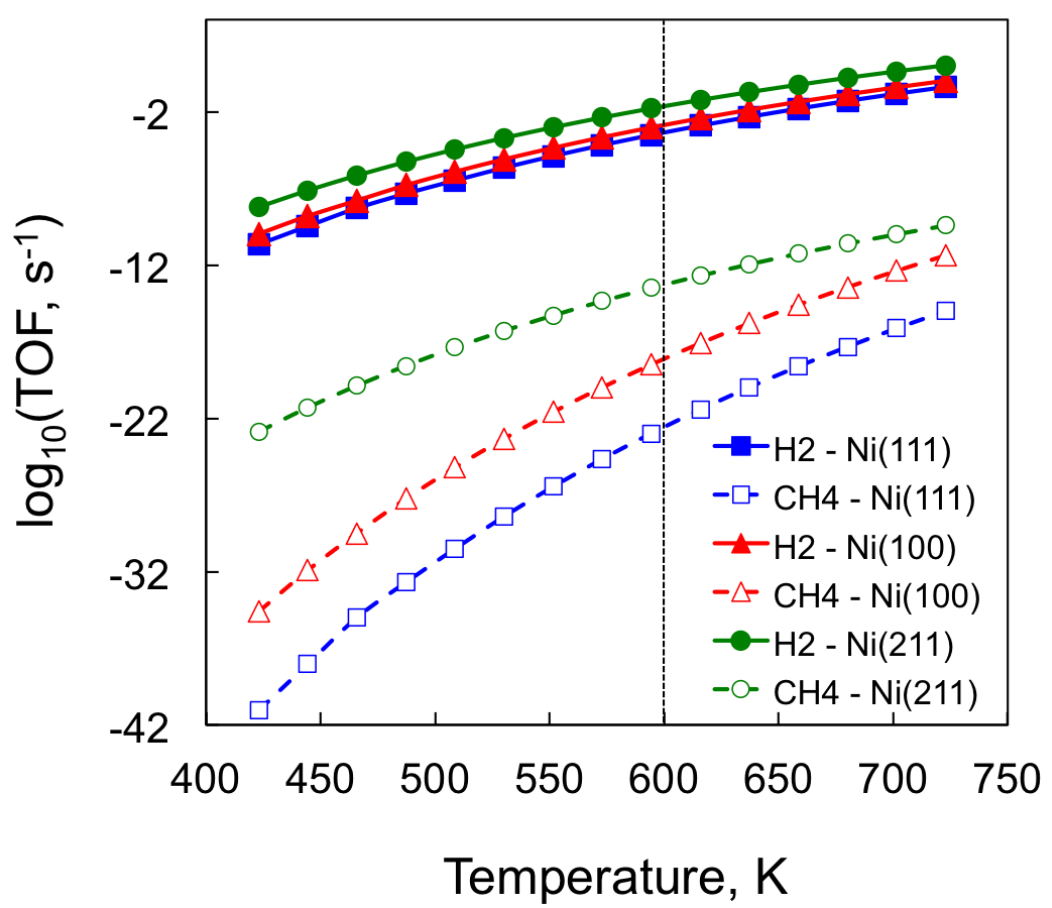

Figure 6. Turnover frequencies $\left(\mathrm{s}^{-1}\right)$ of $\mathrm{H}_{2}$ and $\mathrm{CH}_{4}$ production on $\mathrm{Ni}(111), \mathrm{Ni}(100)$, and $\mathrm{Ni}(211)$ at $1 \mathrm{bar}$, respectively. The feed composition has molar ratio of $\mathrm{CO}: \mathrm{H}_{2} \mathrm{O}=1: 2$. Vertical black dash line marks the reaction conditions of free energy diagram being generated in this paper.

The particle size effect on WGSR and methanation competitions is also investigated by integrating individual $\mathrm{Ni}$ single crystal facets, i.e., $\mathrm{Ni}(111), \mathrm{Ni}(100$, and $\mathrm{Ni}(211)$, to reflect representative fractions of each $\mathrm{Ni}$ atom site on a single $\mathrm{Ni}$ catalyst nanoparticle. The crystal facets can be conveniently combined into truncated cuboctahedra, and the fraction of each facet is dependent on the diameter of the nanoparticle, as shown in Figure 7 (a). With increasing particle sizes, diameter varying from $1 \mathrm{~nm}$ to $8 \mathrm{~nm}$, the fraction of surface atoms decreases from 0.48 to 0.1 (black squares). Correspondingly, the fractions of $\mathrm{Ni}$ atom at the close-packed sites increases from 0.4 to 0.75 (solid orange circles); the $\mathrm{Ni}$ atoms at the open-packed sites increases from 0 to 0.15 ; but the $\mathrm{Ni}$ atoms at the nanoparticle edges decreases from 0.6 to 0.1 .

For instance, the fractions of surface $\mathrm{Ni}$ atoms on $\mathrm{Ni}(111), \mathrm{Ni}(100)$ and $\mathrm{Ni}(211)$ are 0.68 , 0.11 , and 0.21 , respectively (Figure 7 (a)), corresponding to a Ni particle of a diameter of $4 \mathrm{~nm}$. The open sites for each facet are defined as different reaction species within the mechanism, which is demonstrated in the Supporting Information. The TOFs for $\mathrm{H}_{2}$ and $\mathrm{CH}_{4}$ productions as a 
function of particle diameter (in $\mathrm{nm}$ ) are shown in Figure 7 (b) and (c), for a specified temperature and pressure (i.e. $600 \mathrm{~K}$ and 1 bar). In Figure 7 (b) and (c), the production rates of $\mathrm{H}_{2}$ and $\mathrm{CH}_{4}$ both decrease with increasing particle sizes. It can also be noted that, at $600 \mathrm{~K}$ and 1 bar, both the $\mathrm{H}_{2}$ and $\mathrm{CH}_{4}$ production TOFs follow a similar trend of the atomic fraction of $\mathrm{Ni}$ atoms at the (211) sites. For $\mathrm{H}_{2}$ production, the rate (in $\log _{10}$ of TOF) decreases from -2.0 to -3.5 as the nanoparticle diameter increase to $8 \mathrm{~nm}$, while the rate for $\mathrm{CH}_{4}$ changes from -14.0 to -17.5. Therefore, it can also be concluded that the methanation reaction, which depends more on the edge site for $\mathrm{C}-\mathrm{O}$ bond scission, will be more sensitive to the cluster sizes as well.
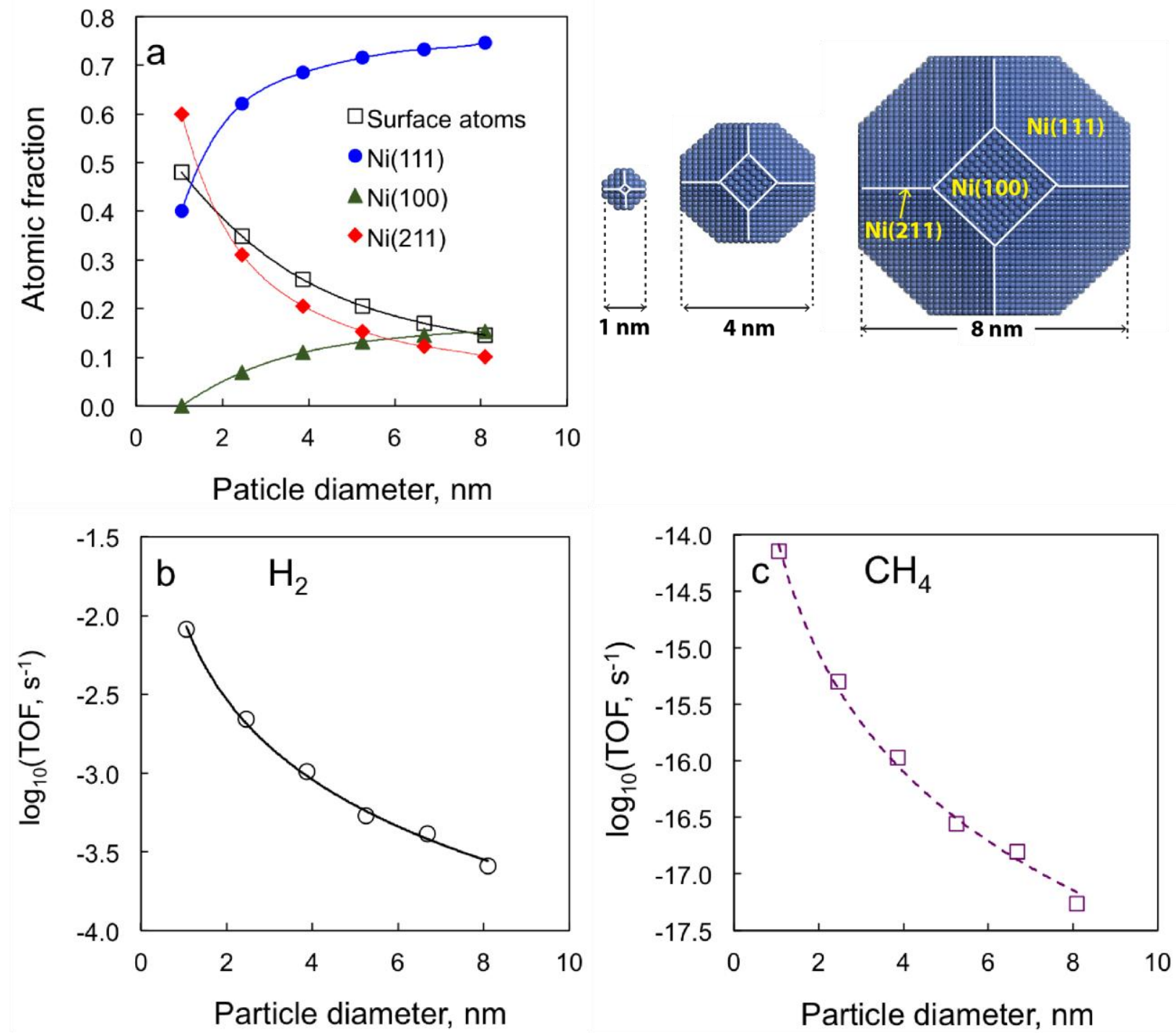

Figure 7. (a) Atomic fractions of surface $\mathrm{Ni}$ atoms (black square), and fractions of $\mathrm{Ni}$ atoms at close-packed (solid orange circle), open-packed (solid green circle), and step edge sites (solid red 
circle) for unsupported $\mathrm{Ni}$ nanoparticles with diameter from $1 \mathrm{~nm} \sim 8 \mathrm{~nm}$. The schematic representations of cuboctahedra of 1,4 , and $8 \mathrm{~nm}$ diameters are also shown; (b) TOF $\left(\mathrm{s}^{-1}\right)$ of $\mathrm{H}_{2}$; and (c) $\mathrm{CH}_{4}$ production at $600 \mathrm{~K}$ and 1 bar. The TOF is the sum of TOF on $\mathrm{Ni}(111), \mathrm{Ni}(100)$ and $\mathrm{Ni}(211)$. The feed composition has molar ratio of $\mathrm{CO}: \mathrm{H}_{2} \mathrm{O}=1: 2$. The solid and dashed lines are simply to guide the trend of modeling results.

\subsection{Feed composition effect on WGSR and methanation}

As discussed in Section 4.2, at high $\mathrm{CO}$ concentration without $\mathrm{H}_{2}$ in the feed, the open sites on Ni surface is dominated by $\mathrm{CO}$. As indicated by Figure 6, the selectivity for hydrogen production is high on all $\mathrm{Ni}$ facets. Typically, the $\mathrm{CO}$ concentration in the reforming product stream will be much lower than the $\mathrm{CO}: \mathrm{H}_{2} \mathrm{O}=1: 2$ ratio used in Section 4.2. Instead, substantial $\mathrm{H}_{2}$ is also present [74, 75]. Feed composition will affect the equilibrium and product selectivity. A different feed composition is used for the microkinetic modeling on the respective $\mathrm{Ni}(111$, $\mathrm{Ni}(100)$, and $\mathrm{Ni}(211)$. The selected composition, i.e., $2.5 \% \mathrm{CO}, 25 \% \mathrm{H}_{2} \mathrm{O}, 12.5 \% \mathrm{CO}_{2}, 37.5 \% \mathrm{H}_{2}$, and balance $\mathrm{N}_{2}$, is based on the values reported in Ref. [35]. Similar to Section 4.2, Figure 8 shows the $\mathrm{H}_{2}$ and $\mathrm{CH}_{4}$ production rate as a function of temperature. $\mathrm{H}_{2}$ production rates on $\mathrm{Ni}(100)$ and $\mathrm{Ni}(211)$ are not shown, as $\mathrm{H}_{2}$ production rates are negative at temperature below $573 \mathrm{~K}$ on $\mathrm{Ni}(100)$, and on $\mathrm{Ni}(211)$ for the entire temperature range considered. The negative $\mathrm{H}_{2}$ production rates can be explained as hydrogen is consumed in $\mathrm{CO}$ methanation at a faster rate than that produced via WGSR on $\mathrm{Ni}(100)$ and $\mathrm{Ni}(211)$ facets. The detail information of $\mathrm{H}_{2}$ and $\mathrm{CH}_{4}$ production rates on each facet is included in Table S5. It can be seen from Figure 8 that the $\mathrm{CH}_{4}$ production rate is temperature dependent, and decreases in the order of $\mathrm{Ni}(211)>\mathrm{Ni}(100)>$ $\mathrm{Ni}(111)$. Comparison of the $\mathrm{CH}_{4}$ production rates in Figure 8 and Figure 6 shows that the $\mathrm{CH}_{4}$ production rates dramatically increase at the new feed composition. This finding reveals that, at low $\mathrm{CO}$ concentration and high $\mathrm{H}_{2}$ concentration, methanation will become a significant competition and lower hydrogen selectivity by consuming $\mathrm{CO}$ and $\mathrm{H}_{2}$, particularly on the lowcoordinated step edge sites and open-packed sites. 


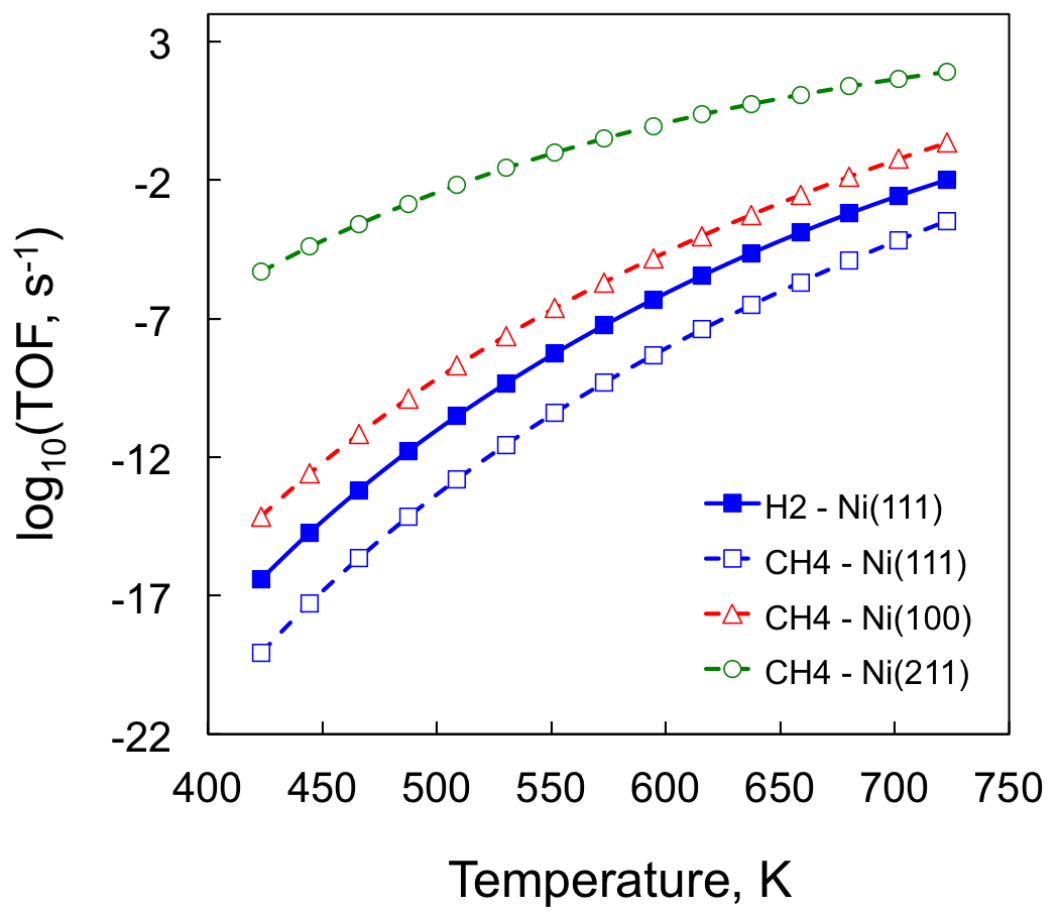

Figure 8. Turnover frequencies $\left(\mathrm{s}^{-1}\right)$ of $\mathrm{CH}_{4}$ production on $\mathrm{Ni}(111), \mathrm{Ni}(100)$, and $\mathrm{Ni}(211)$ at 1bar, respectively. The feed gas molar composition is $2.5 \% \mathrm{CO}, 25 \% \mathrm{H}_{2} \mathrm{O}, 12.5 \% \mathrm{CO}_{2}, 37.5 \%$ $\mathrm{H}_{2}$, and balance $\mathrm{N}_{2}$.

\section{Conclusions}

DFT, statistical calculations and micro-kinetic modeling were carried out for WGSR and methanation on different $\mathrm{Ni}$ facets to understand surface structure and particle size effect for reaction selectivity. Free energy diagrams were generated at $600 \mathrm{~K}$ and 1 bar to study WGSR and methanation reaction thermodynamically and kinetically. The energetics of WGSR and methanation point out that the most favorable facet for redox pathway is $\mathrm{Ni}(100)$ and for carboxyl pathway is $\mathrm{Ni}(211)$. And for methanation pathway, $\mathrm{Ni}(211)$ favors both formyl pathway and $\mathrm{HCOH}$ pathway.

Detailed microkinetic modelings contain favorable pathways for WGSR and methanation on different facet were used to calculate reaction rates under temperature range of 423 to $723 \mathrm{~K}$. The results of the microkinetic model indicate that for temperature, catalyst structure, particle size and feed composition can affect WGSR and methanation. With feed composition of CO : $\mathrm{H}_{2} \mathrm{O}=1: 2$, trends for $\mathrm{H}_{2}$ and $\mathrm{CH}_{4}$ production rate show an increase with increasing temperature 
on all facets, and decrease in the same order as: $\mathrm{Ni}(211)>\mathrm{Ni}(100)>\mathrm{Ni}(111)$. Also, the TOFs of $\mathrm{H}_{2}$ and $\mathrm{CH}_{4}$ production decrease with increasing $\mathrm{Ni}$ particle sizes, whereas methanation is more dependent on the step edge sites on the nanoparticle surfaces. Furthermore, feed composition can also influence $\mathrm{H}_{2}$ and $\mathrm{CH}_{4}$ production rate. The presence of $\mathrm{H}_{2}$ in feed gas favors methanation reaction and can dramatically increase $\mathrm{CH}_{4}$ production rate.

This work implies the detail information for WGSR and methanation on different $\mathrm{Ni}$ facet and particle size. The finding of this work provides fundamental insight of the activity and competition between WGSR and methanation on different facets. The structure sensitivity and particle size effect supply explanation for different catalytic performance. This first-hand information can be used to tune and predict catalyst performance for WGSR and methanation.

\section{Acknowledgements}

This work is supported in part by the Start-up fund provided by Kansas State University, the National Science Foundation under Award No. EPS-0903806, and matching support from the State of Kansas through the Kansas Board of Regents. DFT calculations were carried out thanks to the supercomputing resources and services from the Center for Nanoscale Materials (CNM) supported by the Office of Science of the US Department of Energy under the contract No. DE-AC02-06CH11357; the Beocat Research Cluster at Kansas State University, which is funded in part by NSF grants CNS-1006860; and the National Energy Research Scientific Computing Center (NERSC) under the contract No. DE-AC02-05CH11231. The authors also great appreciate the valuable inputs from Dr. Andrew Medford and the CatMAP support team.

\section{References}

[1] J.P. Breen, R. Burch, H.M. Coleman, "Metal-catalysed steam reforming of ethanol in the production of hydrogen for fuel cell applications", Applied Catalysis B-Environmental, 39 (2002) 65-74.

[2] G.W. Crabtree, M.S. Dresselhaus, M.V. Buchanan, "The hydrogen economy", Physics Today, 57 (2004) 39-44.

[3] P.P. Edwards, V.L. Kuznetsov, W.I.F. David, N.P. Brandon, "Hydrogen and fuel cells:

Towards a sustainable energy future", Energy Policy, 36 (2008) 4356-4362.

[4] N. Hallale, F. Liu, "Refinery hydrogen management for clean fuels production", Advances in Environmental Research, 6 (2001) 81-98.

[5] J.R. Rostrup-Nielsen, "Production of synthesis gas", Catalysis Today, 18 (1993) 305-324. 
[6] H.U. Blaser, C. Malan, B. Pugin, F. Spindler, H. Steiner, M. Studer, "Selective hydrogenation for fine chemicals: Recent trends and new developments", Advanced Synthesis \& Catalysis, 345 (2003) 103-151.

[7] J.R. Rostrup-Nielsen, "Catalytic Steam Reforming", Springer Berlin Heidelberg, 1984.

[8] R.M. Navarro, M.A. Pena, J.L.G. Fierro, "Hydrogen production reactions from carbon feedstocks: Fossils fuels and biomass", Chemical Reviews, 107 (2007) 3952-3991.

[9] M.A. Nieva, M.M. Villaverde, A. Monzón, T.F. Garetto, A.J. Marchi, "Steam-methane reforming at low temperature on nickel-based catalysts", Chemical Engineering Journal, 235 (2014) 158-166.

[10] R.D. Cortright, R.R. Davda, J.A. Dumesic, "Hydrogen from catalytic reforming of biomassderived hydrocarbons in liquid water", Nature, 418 (2002) 964-967.

[11] G.W. Huber, J.W. Shabaker, J.A. Dumesic, "Raney Ni-Sn catalyst for $\mathrm{H}_{2}$ production from biomass-derived hydrocarbons", Science, 300 (2003) 2075-2077.

[12] J.N. Chheda, G.W. Huber, J.A. Dumesic, "Liquid-phase catalytic processing of biomassderived oxygenated hydrocarbons to fuels and chemicals", Angewandte Chemie-International Edition, 46 (2007) 7164-7183.

[13] B. Liu, M. Zhou, M.K.Y. Chan, J.P. Greeley, "Understanding Polyol Decomposition on Bimetallic Pt-Mo Catalysts-A DFT Study of Glycerol", ACS Catalysis, 5 (2015) 4942-4950.

[14] R.A. Lemons, "Fuel cells for transportation", Journal of Power Sources, 29 (1990) 251-264.

[15] R. He, R.R. Davda, J.A. Dumesic, "In situ ATR-IR spectroscopic and reaction kinetics studies of water-gas shift and methanol reforming on $\mathrm{Pt} / \mathrm{Al}_{2} \mathrm{O}_{3}$ catalysts in vapor and liquid phases", Journal of Physical Chemistry B, 109 (2005) 2810-2820.

[16] E.U. Ubong, D. Phillips, M. Gieseke, "CO Poisoning of Pt Electrode in PEM-PBI Based Membrane", ECS Transactions, 26 (2010) 247-255.

[17] J.H. Sinfelt, "Specificity in Catalytic Hydrogenolysis by Metals", 23 (1973) 91-119.

[18] M. Vannice, "The catalytic synthesis of hydrocarbons from $\mathrm{H}_{2} / \mathrm{CO}$ mixtures over the Group VIII metals V. The catalytic behavior of silica-supported metals", Journal of Catalysis, 50 (1977) 228-236.

[19] D. Grenoble, "The chemistry and catalysis of the water gas shift reaction 1 . The kinetics over supported metal catalysts", Journal of Catalysis, 67 (1981) 90-102.

[20] R.R. Davda, J.W. Shabaker, G.W. Huber, R.D. Cortright, J.A. Dumesic, "Aqueous-phase reforming of ethylene glycol on silica-supported metal catalysts", Applied Catalysis B-

Environmental, 43 (2003) 13-26.

[21] A. Haryanto, S.D. Fernando, S.D.F. To, P.H. Steele, L. Pordesimo, S. Adhikari, "Hydrogen Production through the Water-Gas Shift Reaction: Thermodynamic Equilibrium versus Experimental Results over Supported Ni Catalysts", Energy \& Fuels, 23 (2009) 3097-3102. [22] K.-R. Hwang, C.-B. Lee, J.-S. Park, "Advanced nickel metal catalyst for water-gas shift reaction", Journal of Power Sources, 196 (2011) 1349-1352.

[23] O. Arbeladez, T.R. Reina, S. Ivanova, F. Bustarnante, A.L. Villa, M.A. Centeno, J.A. Odriozola, "Mono and bimetallic $\mathrm{Cu}-\mathrm{Ni}$ structured catalysts for the water gas shift reaction", Applied Catalysis a-General, 497 (2015) 1-9.

[24] S.H. Kim, S.-W. Nam, T.-H. Lim, H.-I. Lee, "Effect of pretreatment on the activity of Ni catalyst for $\mathrm{CO}$ removal reaction by water-gas shift and methanation", Applied Catalysis B: Environmental, 81 (2008) 97-104. 
[25] S.D. Senanayake, J. Evans, S. Agnoli, L. Barrio, T.-L. Chen, J. Hrbek, J.A. Rodriguez, "Water-Gas Shift and CO Methanation Reactions over Ni-CeO $\mathrm{C}_{2}(111)$ Catalysts", Topics in Catalysis, 54 (2011) 34-41.

[26] M. Zhou, B. Liu, "DFT Investigation on the Competition of the Water-Gas Shift Reaction Versus Methanation on Clean and Potassium-Modified Nickel(111) Surfaces", ChemCatChem, 7 (2015) 3928-3935.

[27] A.A. Gokhale, J.A. Dumesic, M. Mavrikakis, "On the mechanism of low-temperature water gas shift reaction on copper", J Am Chem Soc, 130 (2008) 1402-1414.

[28] L.C. Grabow, A.A. Gokhale, S.T. Evans, J.A. Dumesic, M. Mavrikakis, "Mechanism of the Water Gas Shift Reaction on Pt: First Principles, Experiments, and Microkinetic Modeling", Journal of Physical Chemistry C, 112 (2008) 4608-4617.

[29] Q.-L. Tang, Z.-X. Chen, X. He, "A theoretical study of the water gas shift reaction mechanism on Cu(111) model system", Surface Science, 603 (2009) 2138-2144.

[30] C.-H. Lin, C.-L. Chen, J.-H. Wang, "Mechanistic Studies of Water-Gas-Shift Reaction on Transition Metals", Journal of Physical Chemistry C, 115 (2011) 18582-18588.

[31] R.C. Catapan, A.A.M. Oliveira, Y. Chen, D.G. Vlachos, "DFT Study of the Water-Gas Shift Reaction and Coke Formation on Ni(111) and Ni(211) Surfaces", The Journal of Physical Chemistry C, 116 (2012) 20281-20291.

[32] R. Carrasquillo-Flores, J.M.R. Gallo, K. Hahn, J.A. Dumesic, M. Mavrikakis, "Density Functional Theory and Reaction Kinetics Studies of the Water-Gas Shift Reaction on Pt-Re Catalysts", ChemCatChem, 5 (2013) 3690-3699.

[33] A. Mohsenzadeh, T. Richards, K. Bolton, "DFT study of the water gas shift reaction on $\mathrm{Ni}(111), \mathrm{Ni}(100)$ and Ni(110) surfaces", Surface Science, 644 (2016) 53-63.

[34] A.B. Mhadeshwar, D.G. Vlachos, "Microkinetic modeling for water-promoted CO oxidation, water-gas shift, and preferential oxidation of $\mathrm{CO}$ on Pt", Journal of Physical Chemistry B, 108 (2004) 15246-15258.

[35] N. Schumacher, A. Boisen, S. Dahl, A.A. Gokhale, S. Kandoi, L.C. Grabow, J.A. Dumesic, M. Mavrikakis, I. Chorkendorff, "Trends in low-temperature water-gas shift reactivity on transition metals", Journal of Catalysis, 229 (2005) 265-275.

[36] M. Ojeda, R. Nabar, A.U. Nilekar, A. Ishikawa, M. Mavrikakis, E. Iglesia, "CO activation pathways and the mechanism of Fischer-Tropsch synthesis", Journal of Catalysis, 272 (2010) 287-297.

[37] M.P. Andersson, E. Abild-Pedersen, I.N. Remediakis, T. Bligaard, G. Jones, J. Engbwk, O. Lytken, S. Horch, J.H. Nielsen, J. Sehested, J.R. Rostrup-Nielsen, J.K. Nørskov, I. Chorkendorff, "Structure sensitivity of the methanation reaction: $\mathrm{H}_{2}$-induced $\mathrm{CO}$ dissociation on nickel surfaces", Journal of Catalysis, 255 (2008) 6-19.

[38] I.A.W. Filot, R.A. van Santen, E.J.M. Hensen, "The Optimally Performing Fischer-Tropsch Catalyst", Angewandte Chemie-International Edition, 53 (2014) 12746-12750.

[39] S. Shetty, A.P.J. Jansen, R.A. van Santen, "Direct versus Hydrogen-Assisted CO Dissociation", Journal of the American Chemical Society, 131 (2009) 12874-12875. [40] M. Stamatakis, Y. Chen, D.G. Vlachos, "First-Principles-Based Kinetic Monte Carlo Simulation of the Structure Sensitivity of the Water-Gas Shift Reaction on Platinum Surfaces", Journal of Physical Chemistry C, 115 (2011) 24750-24762.

[41] A. Mohsenzadeh, K. Bolton, T. Richards, "DFT study of the adsorption and dissociation of water on Ni(111), Ni(110) and Ni(100) surfaces", Surface Science, 627 (2014) 1-10. 
[42] B.R. Cuenya, "Synthesis and catalytic properties of metal nanoparticles: Size, shape, support, composition, and oxidation state effects", Thin Solid Films, 518 (2010) 3127-3150. [43] Y. Xiong, B.J. Wiley, Y. Xia, "Nanocrystals with unconventional shapes - A class of promising catalysts", Angewandte Chemie-International Edition, 46 (2007) 7157-7159. [44] M. Haruta, "Size- and support-dependency in the catalysis of gold", Catalysis Today, 36 (1997) 153-166.

[45] M. Shekhar, J. Wang, W.-S. Lee, W.D. Williams, S.M. Kim, E.A. Stach, J.T. Miller, W.N. Delgass, F.H. Ribeiro, "Size and Support Effects for the Water-Gas Shift Catalysis over Gold Nanoparticles Supported on Model $\mathrm{Al}_{2} \mathrm{O}_{3}$ and $\mathrm{TiO}_{2}$ ", Journal of the American Chemical Society, 134 (2012) 4700-4708.

[46] R.Z.C. Van Meerten, A.H.G.M. Beaumont, P.F.M.T. Van Nisselrooij, J.W.E. Coenen, "Structure sensitivity and crystallite size change of nickel during methanation of $\mathrm{CO} / \mathrm{H}_{2}$ on nickel-silica catalysts", Surface Science, 135 (1983) 565-579.

[47] J. Gao, Q. Liu, F. Gu, B. Liu, Z. Zhong, F. Su, "Recent advances in methanation catalysts for the production of synthetic natural gas", RSC Advances, 5 (2015) 22759-22776.

[48] G. Kresse, J. Hafner, "Ab initiomolecular-dynamics simulation of the liquid-metalamorphous-semiconductor transition in germanium", Physical Review B, 49 (1994) 14251-14269. [49] G. Kresse, J. Furthmüller, "Efficiency of ab-initio total energy calculations for metals and semiconductors using a plane-wave basis set", Computational Materials Science, 6 (1996) 15-50. [50] G. Kresse, D. Joubert, "From ultrasoft pseudopotentials to the projector augmented-wave method", Physical Review B, 59 (1999) 1758-1775.

[51] J.P. Perdew, K. Burke, M. Ernzerhof, "Generalized Gradient Approximation Made Simple", Physical Review Letters, 77 (1996) 3865-3868.

[52] C.R. Henry, "Morphology of supported nanoparticles", Progress in Surface Science, 80 (2005) 92-116.

[53] H.J. Monkhorst, J.D. Pack, "Special points for Brillouin zone integrations", Physical Review $B, 13$ (1976) 5188-5192.

[54] M. Methfessel, A.T. Paxton, "High-precision sampling for brillouin-zone integration in metals", Physical Review B, 40 (1989) 3616-3621.

[55] G. Henkelman, B.P. Uberuaga, H. Jonsson, "A climbing image nudged elastic band method for finding saddle points and minimum energy paths", Journal of Chemical Physics, 113 (2000) 9901-9904.

[56] G. Henkelman, H. Jónsson, "A dimer method for finding saddle points on high dimensional potential surfaces using only first derivatives", The Journal of Chemical Physics, 111 (1999) 7010 .

[57] T.H.-M. Le, B. Liu, L.K. Huynh, "SurfKin: An ab initio kinetic code for modeling surface reactions", Journal of Computational Chemistry, 35 (2014) 1890-1899.

[58] D.A. McQuarrie, "Statistical Mechanics", University Science Books, Sausalito, 2000.

[59] A.J. Medford, C. Shi, M.J. Hoffmann, A.C. Lausche, S.R. Fitzgibbon, T. Bligaard, J.K.

Nørskov, "CatMAP: A Software Package for Descriptor-Based Microkinetic Mapping of Catalytic Trends", Catalysis Letters, 145 (2015) 794-807.

[60] N. Yang, A.J. Medford, X. Liu, F. Studt, T. Bligaard, S.F. Bent, J.K. Norskov, "Intrinsic Selectivity and Structure Sensitivity of Rhodium Catalysts for C2+ Oxygenate Production", Journal of the American Chemical Society, 138 (2016) 3705-3714.

[61] D.S. Newsome, "The water-gas shift reaction", Catalysis Reviews-Science and Engineering, 21 (1980) 275-318. 
[62] S.-C. Huang, C.-H. Lin, J.H. Wang, "Trends of Water Gas Shift Reaction on Close-Packed Transition Metal Surfaces", The Journal of Physical Chemistry C, 114 (2010) 9826-9834. [63] G. Wulff, "On the question of the rate of growth and dissolution of crystal surfaces", Zeitschrift fuer Kristallographie und Mineralogie, 34 (1901) 449-530.

[64] J.K. Nørskov, T. Bligaard, A. Logadottir, S. Bahn, L.B. Hansen, M. Bollinger, H. Bengaard, B. Hammer, Z. Sljivancanin, M. Mavrikakis, Y. Xu, S. Dahl, C.J.H. Jacobsen, "Universality in heterogeneous catalysis", Journal of Catalysis, 209 (2002) 275-278.

[65] T. Bligaard, J.K. Nørskov, S. Dahl, J. Matthiesen, C.H. Christensen, J. Sehested, "The Brønsted-Evans-Polanyi relation and the volcano curve in heterogeneous catalysis", Journal of Catalysis, 224 (2004) 206-217.

[66] B. Liu, J. Greeley, "Decomposition Pathways of Glycerol via C-H, O-H, and C-C Bond Scission on Pt(111): A Density Functional Theory Study", The Journal of Physical Chemistry C, 115 (2011) 19702-19709.

[67] B. Liu, L. Cheng, L. Curtiss, J. Greeley, "Effects of van der Waals density functional corrections on trends in furfural adsorption and hydrogenation on close-packed transition metal surfaces", Surface Science, 622 (2014) 51-59.

[68] J.G. Xu, G.F. Froment, "Methane steam reforming, methanation and water-gas shift .1. Intrinsic kinetics", AIChE Journal, 35 (1989) 88-96.

[69] Z.L. Zhang, M. Baerns, "Hydrogen formation by steam-reforming and water gas shift reaction in the oxidative methane coupling reaction over calcium-oxide cerium dioxide catalysts", Applied Catalysis, 75 (1991) 299-310.

[70] Y. Huang, C. Ling, M. Jin, J. Du, T. Zhou, S. Wang, "Water adsorption and dissociation on Ni surface: Effects of steps, dopants, coverage and self-aggregation", Physical Chemistry Chemical Physics, 15 (2013) 17804-17817.

[71] J. Sehested, S. Dahl, J. Jacobsen, J.R. Rostrup-Nielsen, "Methanation of CO over nickel: Mechanism and kinetics at high $\mathrm{H}_{2} / \mathrm{CO}$ ratios", Journal of Physical Chemistry B, 109 (2005) 2432-2438.

[72] M.A. Vannice, "Catalytic synthesis of hydrocarbons from $\mathrm{H}_{2}-\mathrm{CO}$ mixtures over group-8 metals .2. Kinetics of methanation reaction over supported metals", Journal of Catalysis, 37 (1975) 462-473.

[73] J.-H. Lin, P. Biswas, V.V. Guliants, S. Misture, "Hydrogen production by water-gas shift reaction over bimetallic $\mathrm{Cu}-\mathrm{Ni}$ catalysts supported on La-doped mesoporous ceria", Applied Catalysis a-General, 387 (2010) 87-94.

[74] A. Wawrzetz, B. Peng, A. Hrabar, A. Jentys, A.A. Lemonidou, J.A. Lercher, "Towards understanding the bifunctional hydrodeoxygenation and aqueous phase reforming of glycerol", Journal of Catalysis, 269 (2010) 411-420.

[75] J. Comas, F. Marino, M. Laborde, N. Amadeo, "Bio-ethanol steam reforming on $\mathrm{Ni} / \mathrm{Al}_{2} \mathrm{O}_{3}$ catalyst", Chemical Engineering Journal, 98 (2004) 61-68. 